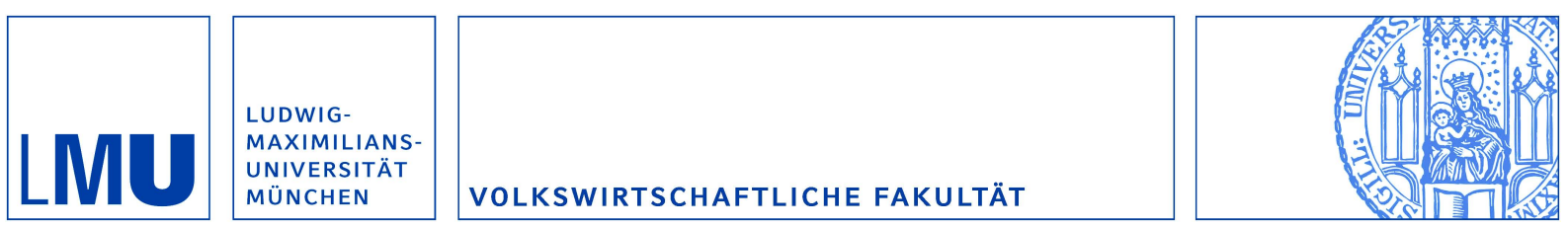

Grün, Carola und Klasen, Stephan:

Growth, Income Distribution, And well-Being In Transition Countries

Munich Discussion Paper No. 2000-14

Department of Economics

University of Munich

Volkswirtschaftliche Fakultät

Ludwig-Maximilians-Universität München

Online at https://doi.org/10.5282/ubm/epub.26 


\title{
Growth, Income Distribution, and Well-Being in Transition Countries
}

\author{
Carola Grün \\ and \\ Stephan Klasen
}

Draft as of November 27, 2000

Note:

This paper is a revised and focused version of a paper presented at the 2000 IARIW Conference in Cracow. The original paper presented was called 'Growth, Income Distribution, and Well-Being: Comparisons across Space and Time' (which will remain a stand-alone paper). While the original paper dealt with well-being comparisons across all countries of the world (and at a global level), this revised and focused version is entirely concentrated on Transition Countries.

For additional information please contact:

Stephan Klasen

Department of Economics

University of Munich

80539 Munich

Germany

Email: Klasen@1rz.uni-muenchen.de

Fax: +49-89-2180-3954

Tel:+49-89-2180-2459

Acknowledgements

We would like to thank Tony Atkinson for helpful discussions on this topic. In addition, we want to thank Klaus Deininger for providing an update to the Deininger-Squire dataset, Branko Milanovic for providing country data sheets for transition countries, and Thesia Garner for organizing the session at the IARIW Cracow Meetings. Finally, we thank Andrea Brandolini, Thesia Garner, Stephen Jenkins, Branko Milanovic, Lars Osberg, Graham Pyatt, Utz-Peter Reich, and Michael Ward for helpful comments on an earlier version of this paper. 


\begin{abstract}
In this paper we use several well-being measures that combine average income with a measure of inequality to undertake international and intertemporal well-being comparisons in transition countries. Our well-being measures drastically change the impression of levels and changes in well-being from a traditional reliance on income measures. They also significantly affect the ranking of countries, when compared to rankings based on real incomes. Due to low inequality and moderate income levels, socialist countries enjoyed relatively high levels of economic well-being. In the transition process, rising inequality and falling incomes have led to a dramatic decline in well-being in many transition countries, and a corresponding worsening in rank when compared to other countries. There is great variance in the income and inequality performance of transition countries. We find a close correlation between income losses and inequality increases suggesting the ability of appropriate policies to reduce the income losses and reduce rising inequality. While the political dimension of transformation remains largely successful, our indicators suggest that most transition countries have yet to reach the level of economic well-being enjoyed in the late 1980s.
\end{abstract}

\title{
1. Introduction
}

It is well-known that many transition countries ${ }^{1}$ suffered from severe contractions in income levels. While in some countries, the economies have stabilized and returned to positive income growth, in others the contraction has continued to this day. By 1998, only six countries have managed to surpass their per capita income level they had in 1988 (see Figure 1); many are still between 20-50\% below that level. In fact, Milanovic (1998) demonstrates that the income losses suffered by many transition countries are higher and more persistent than they were during the Great Depression in the Western capitalist world.

At the same time, income inequality has increased in most transition economies, a subject that has also received considerable attention in the literature (e.g. Milanovic, 1998; Atkinson and Micklewright, 1992; Flemming and Micklewright, 2000; Klasen, 1994a). The welfare economic implications of these two developments, declining incomes and rising inequality, has been studied much less. A broad range of philosophical approaches to the measurement of welfare (ranging from utilitarianism with some very reasonable assumptions about utility functions to Rawlsian reasoning or Sen's capability approach) would suggest that, ceteris paribus, rising income inequality reduces aggregate well-being. In fact, there exist a range of measures for well-being that make use of this insight and combine mean income with some measure of income inequality to arrive at better measures of welfare than average income alone (e.g. Atkinson, 1970; Sen, 1973; Dagum, 1990; Ahluwalia and Chenery, 1974). Using insights from this literature, this paper applies indicators of income and income distribution to transition countries to arrive at a more accurate summary assessment of well-being, and changes in well-being, than either of these measures alone would allow.

We find that the measures that include income inequality in the assessment of well-being have a significant influence on absolute levels of well-being, comparisons of well-being among transition countries, and between transition countries and comparable middle-income countries. Prior to the transition, moderate income levels and low inequality translated into fairly high levels of well-being as measured by our indicators. The nature of income inequality in socialist countries also differed to other countries and was characterized by particularly high income shares of the poorest quintile. After the transition, reduced income levels and much higher inequality has

\footnotetext{
${ }^{1}$ We will focus our attention on the transition countries of Eastern Europe and the former Soviet Union. Countries such as China, Vietnam, and Laos are not considered here.
} 
led to a dramatic worsening in ranking of most transition countries. This decline in ranking is much more pronounced for most successor states of the Soviet Union than for Central and Eastern European countries. Moreover, deteriorations in well-being are understated using income measures alone. Once worsening inequality is considered, the well-being losses in transition countries are magnified. In that context, we note that there appears to be a positive correlation between the level of income loss and the deterioration of inequality. Thus our indicators generally accentuate difference between the poor economic performers who often had sharply rising inequality and the better economic performers who tended to have more moderate increases in inequality. Finally, there appears to be fairly close agreement between our measure of well-being and other indicators of human development that go beyond the focus on income (see also Klasen, 1994a). In contrast, indicators of political and civil liberties have improved dramatically and are thus at variance with the changes in economic well-being indicators in transition countries.

It should be pointed out at the start that this paper presents tentative results on a matter that is far from settled. On the theoretical side, we do not wish to propose definitive measures of wellbeing. Clearly, our measures that merely combine income and its distribution are fairly limited and cannot pretend to fully capture all aspects of well-being, not even all economically relevant aspects of well-being. ${ }^{2}$ Instead, we merely wish to illustrate how reasonable ways of incorporating inequality in an assessment of well-being will change our impression of well-being across space and time. On the empirical front, our conclusions should be seen as equally tentative. We have to rely on imperfect data on both income levels and income distribution. For transition countries, a number of additional problems of data reliability as well as interpretation arise. In particular, there are question as to the reliability and appropriate interpretation of comparisons of income inequality in socialist and capitalist countries. Moreover, it is not clear that pre- and posttransition data on income inequality (or income, for that matter) can easily be compared (see Flemming and Micklewright, 2000, Milanovic, 1998). Some of these issues will be discussed below, but clearly these are difficult question that are far from resolved.

The paper is organized as follows: the next section discusses the theoretical issues involved in comparing well-being across space and time. Section 3 discusses the measures of well-being we use in this paper. Section 4 presents the data and our manipulations for this analysis. Section 5 contains the results for the international analysis, section 6 describes the sensitivity analysis, section 7 illustrates comparisons across time, and section 8 concludes.

\section{The Theory of Well-Being and Real-Income Comparisons}

Despite a long history, the theory of well-being comparisons across space and time continues to be beset with conceptual and practical problems. Ever since it became evident that social choice theory was not yielding acceptable ${ }^{3}$ procedures for making comparative or intertemporal social welfare judgements, social welfare judgements have been based on axiomatic approaches to welfare measurement. Those are based on a conceptualization of what constitutes welfare and the subsequent derivation of an indicator that, under certain stated assumptions, can adequately measure the chosen concept.

Applying such measures to comparisons across space and time generate additional problems (Sen 1982, 1984). In particular, the theory of welfare comparisons is based on simultaneous situational comparisons undertaken by the same people, while intertemporal

\footnotetext{
${ }^{2}$ See Osberg and Sharpe (2000) for a more ambitious approach to the measurement of economic well-being in OECD countries.

${ }^{3}$ Acceptable is meant in the sense of obeying minimal requirements such as the four conditions stated by Arrow in his famous impossibility result (Arrow, 1963). See also Sen $(1973,1999)$ for a discussion.
} 
comparisons ass the well-being of the same people at different points in time, and international comparisons assess the well-being of different persons. ${ }^{4}$ In addition to this theoretical problem, the comparability of prices throws up an additional problem, namely of the appropriate exchange rate for international comparisons. Until recently, most real income comparisons were based on official exchange rates despite the knowledge that they are often distorted as a result of speculation and currency restrictions, and that they imply a systematic underevaluation of the nontraded sector in poorer countries. In recent years, the ICP Project has generated purchasing power parity estimates of GDP and GNP based on international prices that try to address these particular short-comings. ${ }^{5}$ Purchasing Power Parity approaches should also lead to improved estimates of GNP and GDP in pre-transition economies where the domestic prices were substantially different from prices in market economies (Summers and Heston, 1991). ${ }^{6}$

The most commonly used indicator for welfare comparisons across space and time is real per capita income. ${ }^{7}$ It can be derived from utilitarian welfare economics using three alternative sets of assumptions. One set would demand everyone to have identical unchanging cardinal utility functions where income (or consumption) ${ }^{8}$ enters the utility function linearly (e.g. in the simplest form, every unit of consumption generates one unit of utility). An alternative set of assumptions could allow for more realistic concave utility functions, but would still require identical utility functions and require in addition that everyone is earning the per capita income and thus consumes the mean commodity bundle (Sen, 1984). A third set is based on Samuelson (1947) and takes an 'individualistic approach' to welfare measurement. Under this approach, we recover social welfare from individual welfare based on revealed preferences using the Pareto principle. If preferences are complete, convex, and monotonically increasing, if each person's welfare only depends on their purchases (i.e. no externalities and public goods), if there are no market imperfections on the buyer's side, and if each person is rational in the sense that her choices reflect her welfare ranking, then the ratio of market prices should equal the ratio of intrapersonal weights (marginal rates of substitution) attached to these goods. These assumptions are not sufficient, however, to ensure that the market prices say anything about the valuation of a good going to two different people, as this requires interpersonal comparisons. To be able to make such interpersonal comparisons which is required for all real income comparisons, we need to assume in addition that the income distribution is 'optimal' to 'keep the ethical worth of each person's marginal dollar equal' (Samuelson, 1947:21).

\footnotetext{
${ }^{4}$ A situational comparisons asks whether a person would hypothetically prefer situation A to B. This comparison thus takes place at the same time and is done by the same person. Intertemporal or international welfare comparisons, however, address different questions. Intertemporal comparisons have to contend with the problem that the persons are not evaluating the welfare of two situations simultaneously, but sequentially. This may generate problems if overall perceptions of welfare or tastes have changed over time (in addition to the problem that not all the people are alive in both periods). Comparisons across space, as done in inter-country comparisons, are even more difficult as now the persons differ whose welfare is being compared and we know little about differences in their preferences. In addition, the comparison could be made using the price (or other welfare weight) vectors of either country, which would not necessarily generate the same result. For details, see Sen $(1982,1984)$.

${ }^{5}$ While these data generated by these methods are widely used, they are not beyond question. In particular, the resulting adjusted per capita incomes are sensitive to the choice of 'international prices' which is closer to the prices prevailing in rich countries (Berry, Bourguignon, and Morrison, 1991). Moreover, PPP adjustments can differ in their outcomes as differences between the World Bank estimates and the Penn World Tables demonstrate (see below).

${ }^{6}$ At the same time, such comparisons will still have to face the problem of different product quality between socialist and capitalist economies, which might lead to an overstatement of incomes in socialist countries. For a discussion see (Summers and Heston, 1991).

${ }^{7}$ There are well-known omissions of GNP as a measure of value created in the economy. These issues will not be discussed further here.

${ }^{8}$ We abstract from the difficulties associated with the treatment of saving in an indicator of welfare. See for example, the paper by Osberg and Sharpe (2000).
} 
All three sets of assumptions are beset with problems. While many aspects of the various sets of assumptions appear unrealistic, the need to explicitly ignore the distribution of income in a welfare comparison appears particularly unpalatable in all three sets of assumptions. Ignoring income distribution through the assumption of linear utility functions, through the assumption of everyone having the same income, or through the assumption of income distribution being 'optimal' from a welfare point of view is all equally problematic. In fact, both theoretical considerations (e.g. declining marginal utility of income derived from convex preferences) as well as empirical observations (e.g. about risk aversion and insurance) clearly suggest that the existing distribution of incomes is not 'optimal' from a social welfare point of view, or that utility functions are linear in income or consumption. Instead, these theoretical and empirical considerations point to concave utility functions, i.e. that inequality reduces aggregate welfare as the marginal utility of income among the poor is much higher than among the rich. ${ }^{9}$

Non-utilitarian views of welfare would also suggest that income inequality reduces aggregate well-being. For example, Sen's capabilitity approach (Sen, 1987) which calls for a maximization of people's capability to function (e.g. the capability to be healthy, well-nourished, adequately housed, etc.) also exhibits declining marginal returns in the income space. ${ }^{10}$ Similarly, application of Rawlsian principles would also suggest that welfare is higher in societies where inequality is lower (Rawls, 1971). ${ }^{11}$

One approach to improve upon the welfare content of real income comparisons is therefore to jettison this neglect of income distribution and incorporate the notion of declining marginal welfare returns of income. Each of the measures proposed in the next section does precisely this in slightly different ways.

Before turning to this issue, however, it may be useful to consider one explicit objection to the incorporation of distributional issues in an assessment of well-being. In particular, it may be argued that redistributions reduce the long-term growth potential of an economy so that there may be a trade-off between higher well-being associated with lower inequality today and lower wellbeing associated with the subsequently reduced economic growth. While such dynamic considerations go beyond the scope of this analysis and would, in any case, require the inclusion of other dynamic issues (e.g. the role of savings and of depreciation of human, natural, and physical capital in long-term well-being of nations) $)^{12}$, there is a growing consensus that this tradeoff between distribution and growth does not, in fact, exist. In fact, if anything, the debate has recently shifted in the opposite direction suggesting that initial inequality lowers subsequent growth prospects rather than increases them (e.g. Deininger and Squire, 1997; Alesina and Rodrick, 1994; Clarke, 1995; Persson and Tabellini, 1994; Klasen, 1999). While these findings are still tentative and subject to some debate ${ }^{13}$, they suggest that the older claim, that high

\footnotetext{
${ }^{9}$ This is inherent also in the approach by Graaf (1957) and Sen (1982) who treat the same good going to two different people as two different goods and thus explicitly do away with the distinction between size and distribution of income as the 'welfare depends on them both'. (Sen, 1982).

${ }^{10}$ For example, there appears to be a concave relationship between income and life expectancy, and income and educational achievement. For a discussion, see Klasen (1994b).

${ }^{11}$ In the lexicographic version of the maximin principle, only the position of the worst off is relevant; if one generalizes a bit, one would get a more continuous declining marginal valuation of income. Similarly, Hirsch's views on the social limits to growth also imply declining aggregate well-being as a result of inequality. For details see Hirsch (1977) and Klasen (1994b).

${ }^{12}$ One might also want to consider longevity in conjunction with income and income inequality to measure for how long people are able to enjoy the incomes they enjoy. For a discussion, see Berry, Bourguignon, and Morrison, (1991).

${ }^{13}$ See, for example, Lundberg and Squire (1999) who regard growth and income inequality as jointly determined rather than one causing the other; they also find that inequality is particularly bad for income growth among the poor,
} 
inequality is essential for high subsequent economic growth, does not seem to be borne out by the weight of the evidence (see also Klasen, 1994b).

\section{The Well-Being Measures Used}

In this section we describe some measures that jointly consider per capita income and its distribution and therefore avoid the particularly problematic neglect of income distribution in a consideration of welfare. Most are well-known in the inequality literature although not all of them have been used explicitly for aggregate welfare comparisons. All share the feature that they can be summarized by the following formula:

$W=\mu(1-I)$ where: $0 \leq I \leq 1$

Welfare is a function of mean income $\mu$, reduced by a measure of inequality I. Thus inequality adjusts mean income downward to reflect the welfare loss associated with the (unequal) distribution of that mean income. We will consider several measures because the different measures not only differ in the intensity of the 'welfare penalty' they impose but also (implicitly) in the penalty they impose for different types of inequality.

The first measure considered is proposed by Sen (1982) and incorporates inequality through the Gini coefficient. This Sen measure can be stated as:

$S=\mu(1-G)$ where $\mu$ is the mean income and $G$ is the Gini coefficient.

The Sen measure can be derived by replacing Samuelson's problematic 'optimal distribution' assumption by the assumption of 'rank order weighting' (Sen, 1973). Individual incomes will be weighted according to their rank in the income distribution (with the richest receiving rank 1 and thus the lowest weight for their income). It can also be derived from a utility function where individuals consider not only their own incomes, but the entire income distribution, with particular emphasis on the number of people with incomes below or above one's own (Dagum, 1990). Thus preferences are assumed to be interdependent which accords well with recent empirical findings (e.g. Easterlin, 1995; Banerjee, 1997).

A variant of this measure was proposed by Dagum (1990):

$D=\frac{\mu(1-G)}{1+G}=\mu\left(1-\frac{2 G}{1+G}\right)$.

Clearly, the Dagum measure is a more extreme version of the Sen measure as it imposes a higher penalty for inequality as the denominator imposes an additional penalty for inequality. The Dagum measure can also be based on interdependent preferences and additionally implies that people receive a further welfare penalty from the people ahead of them in their income distribution which also appears to be a reasonable assumption. ${ }^{14}$

In addition, we consider two versions of the Atkinson welfare measure. The Atkinson measure was developed as an indicator of inequality that explicitly considers the welfare loss associated with inequality in the measure (Atkinson, 1970). But one can equally well just use the way the welfare loss is calculated, the equally distributed equivalent income (EDEA), as the welfare measure itself. ${ }^{15}$ This equally distributed equivalent income is the amount of income that,

while it has a different effect for income growth among the rich. See also Forbes (2000) who finds evidence that the trade-off does indeed exist.

${ }^{14}$ See Dagum (1990) for a derivation and justification of this measure.

${ }^{15}$ This has been done, for example, by UNDP in deriving the gender-related development index (UNDP, 1995). For a discussion, see Bardhan and Klasen (1999). 
if distributed equally, would yield the same welfare as the actual mean income and its present (unequal) distribution (Deaton, 1997). The general form of this measure is ${ }^{16}$ :

$A 2=E D E A 2=\left[\frac{1}{N} \sum_{i=1}^{N} x_{i}^{1-\varepsilon}\right]^{\frac{1}{1-\varepsilon}}$

This measure depends crucially on the exponent $\varepsilon$, the aversion to inequality factor. The higher $\varepsilon$, the higher penalty for inequality. We consider two cases, $\varepsilon=2$ (A2), and $\varepsilon=1$ (A1). In the latter case, the general form of the Atkinson measure is not defined and for this case the measure changes to:

$$
\ln (A 1)=\ln (E D E A 1)=\frac{1}{N} \sum_{i=1}^{N} \ln \left(x_{i}\right)
$$

The Atkinson measures can be derived from social welfare functions that are additively separable functions of individual incomes. Thus they are based on individualistic utility functions where people only care about their own incomes. Inequality reduces welfare in this formulation as the utility functions considered are concave for all $\varepsilon$ greater than 0 . All the measures exhibit constant relative risk aversion. The $\varepsilon=1$ has the additional property of being based on a constant elasticity utility function, suggesting that a percentage increase in income is valued the same regardless of its recipient. Such an assumption has quite a lot of intuitive appeal (see below). While clearly $\varepsilon=2$ penalizes inequality more than $\varepsilon=1$ and is thus based on declining elasticity of income, the underlying assumption, that at twice the level of income, a percentage increase in income is valued half as much as at the lower level of income which also appears to be within the range of reasonable assumptions (see Deaton, 1997 and UNDP, 1995). Such penalties of inequality are still consistent with findings from the micro literature on utility and risk. Most of the non-utilitarian theories suggested above would, in fact, likely require considerably higher inequality aversion. ${ }^{17}$ While the Atkinson measures are typically based on individual incomes, our $N$ refers to the five income quintiles, the only information we have available for the analysis. ${ }^{18}$

Before turning to the data and the results, it is important to briefly discuss the most important differences between the measures. ${ }^{19}$ Apart from the penalty applied to inequality, the two Gini-based measures differ quite fundamentally from the two Atkinson measures (and thus the Ahluwalia and Chenery measures) in ways that are important to consider. First, the two sets of measures respond differently to equal-sized income transfers at different points in the income

\footnotetext{
${ }^{16}$ Also, this measure satisfies the general form of the well-being measure $\mathrm{W}=\mu(1-\mathrm{I})$ where $\mathrm{I}=1-\mathrm{A} / \mu$. See Atkinson (1970).

${ }^{17}$ A strict interpretation of Rawls lexicographic maximin principle would require $\varepsilon$ to be infinite (see also Atkinson, 1970).

18 A third set of measures were proposed by Ahluwalia and Chenery (1974). They proposed a measure which they called a population-weighted or equal-weighted growth rate which is simply the arithmetic average of the growth rates of each individual (or quintile). Instead of treating a dollar increase the same regardless of its recipient, this measure treats a percentage increase the same, thus also allowing for declining marginal utility of income and exhibiting what Ahluwalia and Chenery called the 'one person, one vote' principle of growth measurement. It turns out that this measure is a small-number approximation of the Atkinson $\varepsilon=1$ measure. The similarity between this measure and the Atkinson measure gives another quite nice justification for the Atkinson measure. Similarly, their second well-being measure, the welfare or poverty-weighted growth rate (which gives greater weight to income increases of the poor than the rich) is a discrete approximation of a version of the Atkinson with $\varepsilon>1$. Our A2 measure will therefore yield very similar results. For details, see Klasen (1994b) and Grün and Klasen (2000).

${ }^{19}$ For a more extensive discussion of these issues, refer to Atkinson (1970), Blackorby and Donaldson (1978) and Dagum (1990).
} 
distribution. While all measures are consistent with the Dalton principle of transfers ${ }^{20}$, the Atkinson measures obey what has been called 'transfer sensitivity', which means that an equal sized transfer will have a larger impact on inequality (and thus on welfare) if it happens among the poorer sections of the income distribution than if it happens among richer sections (Sen, 1997). Most would agree that this is a desirable property.

In contrast, the largest impact of an equal sized transfer using the Gini coefficient will be among the mode of the income distribution, i.e. among middle income groups as these transfers will have the largest impact on the rank of the people affected by the transfer and thus the weights attached to their incomes (see Atkinson, 1970; Blackorby and Donaldson, 1978). While there is some justification for this (if income comparisons with others are very important, clearly shifts in income which have a large impact on the ranking should be weighed heavily), most analysts see this as a rather undesirably property of the Gini-based measures. ${ }^{21}$

Second, the Atkinson measures are sub-group consistent and thus imply that any increase in the income of a subgroup (or a reduction in inequality of that subgroup) will, ceteris paribus, raise aggregate welfare. In contrast, an increase of income accruing to the richest could actually lower aggregate welfare in the Gini-based measures as the increase in mean income can be more than off-set by the increase in inequality. ${ }^{22}$ Some see this as an argument in favor of the Ginibased measures (e.g. Sen, 1997, Dagum, 1990), others see subgroup consistency as a valuable property. For our purposes it will suffice to note that the Gini-based measures penalize inequality more if middle income groups are hurt the most, while the Atkinson measure will penalize more if the poorest are hurt the most by it. Which measure presents a better approximation of the impact of income and its distribution on well-being is left for the reader to decide.

We will use these measures in three different ways. First, we will simply see how much the incorporation of inequality reduces our impression of aggregate well-being. We will therefore present data on how much well-being is reduced in a country at a point in time by the amount of inequality that is present. This can be achieved by simply presenting the ratio of inequalityadjusted per capita income (as calculated using our four measures) to the unadjusted per capita income. Second, we will examine to what extent the incorporation of inequality changes the ranking of countries. Here, we will compare transition countries with a set of comparable countries from Europe and the developing world. ${ }^{23}$ Third, we will study to what extent the inclusion of inequality in the well-being measure will affect our impression of changes in wellbeing in selected transition countries.

\footnotetext{
${ }^{20}$ The Dalton principle of transfers states that an inequality measure must be reduced by a transfer from a richer person to a poorer person without changing their position in the income ranking.

${ }^{21}$ For a discussion, see Sen (1997).

${ }^{22}$ See Dagum (1990) for examples. This difference only appears if inequality is much more extreme than the types of inequality existing in today's world.

${ }^{23}$ These countries include Spain and Portugal, the countries in Western Europe that were quite similar in income levels prior to the transition, as well as most middle-income developing countries, which now have similar income levels to transition economies. We also include China since it is also a transition economy, and since it has similar income levels to some of the poorer former Soviet Republics.
} 


\section{The Data}

For most of the analysis, we rely on three different cross-country data sets. We use per capita Gross National Product as the basis of our income comparison. ${ }^{24}$ Those income data are PPP adjusted per capita incomes primarily based on the World Bank's World Development Indicators, (World Bank, 1999). For 1980, we will also compare them to income data from the Penn World Table, mark 5.6 (NBER, 2000). As we focus on the transition period, we will concentrate on the period from 1980 to $1995 .^{25}$

Information about income distribution is not as readily available. For data on transition countries for the years 1988 and 1995, we rely on the data set produced by Milanovic (1998). While this data set is clearly not beyond reproach (see below), it is custom-made for the analysis of inequality trends in transition countries and is therefore likely to be the most consistent available source. It provides detailed information on Gini coefficients and decile shares of income. In addition, it is one of the few data sets that specifically address the problem of the many boundary changes in the transition process and report on data of the newly created entities prior to the transition. Most secondary sources on inequality, including Deininger and Squire (1996, 1998) and Wider's World Income Inequality Database (Wider, 1999) rely on Milanovic as their main primary data source for transition countries.

There are a range of questions associated with the reliability, consistency, and compatibility of the pre- and post-transition datasets. First, there is the question of the reliability of income distribution data in socialist (i.e. pre-transition) economies, and its compatibility with income distribution information in Western countries. This issue is addressed in detail in Atkinson and Micklewright (1992) and Flemming and Micklewright (2000). They find that the data on inequality of household incomes in most Central and Eastern European countries was of no worse quality than comparable data in Western countries. In the Soviet Union, the data were somewhat less reliable, particularly due to a problematic sampling frame. Regarding the interpretation of compatibility of income distribution data in socialist and Western countries, there are questions as to whether the income distribution data in socialist countries understate true inequality as they ignore the effect of sizeable in-kind transfers and do not account for pervasive problems of rationing and possibly unequal access to goods by different groups of the population. Both studies find, however, that in-kind earnings were not significantly more important in socialist countries than elsewhere, and were not generally more unequally distributed. The effect of rationing also was not invariably understating income inequality so that they conclude that there is no strong case to be made that income distribution data from social countries systematically understate true inequality, when compared with Western data (Atkinson and Micklewright, 1992; Flemming and Micklewright, 2000; see also Milanovic, 1998). ${ }^{26}$

Regarding post-transition data, different questions emerge. One is the reliability of income information in transition countries, given that the survey instruments had to be adapted considerably and might not be able to adequately capture the changing composition of incomes.

\footnotetext{
${ }^{24}$ GNP is preferred to GDP as an indicator of welfare of a country, as the former includes factor incomes of residents abroad while is excludes factor incomes by non-residents.

${ }^{25}$ We express all data in constant 1995 prices using the US GDP deflator.

${ }^{26}$ The effect of rationing and poor product quality might also have an influence on comparisons of per capita incomes between socialist and capitalist countries. One might argue that the same level of per capita income generates more well-being in the West as one can spend this income without having to face rationing and products of poor quality. The size of this potential bias in hard to quantify. In contrast, socialist countries provided a range of well-being relevant public goods (education, health care, etc) at low or zero costs which might off-set this bias (Klasen, 1994a; Sen, 1991).
} 
While this may be a problem in some countries ${ }^{27}$, most observers agree that the reliability of income data in Eastern European transition countries has not changed for the worse, and improved in some countries, notably where new survey instruments were developed or the existing ones reformed (see Flemming and Micklewright, 2000; Milanovic, 1998). ${ }^{28}$ In most of the successor states of the Soviet Union, the data sources are new surveys or improved versions of the old budget surveys; in Moldova and the Central Asian Republics (except Kyrgyz Republic), the old and somewhat problematic budget surveys are used as new representative sources are not available (Milanovic, 1998).

Another problem is the time period on which Gini coefficients for the post transition years are based on. Unfortunately, for this period annual data were only available in nine countries, and therefore the calculations have to rely on semiannually, quarterly, and even monthly income data (Milanovic, 1998). Gini coefficients based on shorter periods in time will overestimate inequality, because fluctuations in income cannot be smoothed out that easily over shorter time periods. Finally, post-transition data are mostly based on disposable income while pre-transition data were mostly based on gross incomes. This should not affect compatibility greatly as personal taxes (the most important difference between gross and disposable incomes) were comparatively small in socialist countries. ${ }^{29}$

Milanovic (1998) considers these and other problems of compatibility and concludes that the net result appears to be that increases in inequality between before and after the transition might be somewhat overestimated in Poland, the Czech Republic, Hungary, Romania, Russia, the Baltic Republics, Belarus, Ukraine, and the Kyrgyz Republic, while there is likely to be no or an unclear bias in Slovakia, Slovenia, Bulgaria, Moldova, Kazakhstan, Turkmenistan, and Uzbekistan. ${ }^{30}$ Moreover, the general sense is that inequality data in post-transition countries are fairly comparable with inequality information in Western countries, esp. since now the surveys share very similar short-comings to those in Western countries (Flemming and Micklewright, 2000). ${ }^{31}$ We will partly address these issues of compatibility in the sensitivity analysis where we compare the data we used with other available sources of inequality data.

A final problem might emerge with our approach of using benchmark years for comparisons of well-being. While in most non-transition countries inequality appears to have been fairly stable over time (Deininger and Squire, 1998), this is not the case in transition countries. As a result of increasing inequality, it will matter which year is chosen as a benchmark (Flemming and Micklewright, 2000). Fortunately, all available information on trends in inequality over time (see Flemming and Micklewright 2000 and also Appendix 2) suggests that the post-transition years included in Milanovic (usually 1993-1995) are from years where the biggest increases in inequality have already happened; after those years, most studies find only small further increases. Moreover, to the extent that inequality has increased further after the

\footnotetext{
${ }^{27}$ For example, there appears to be no representative source on household per capita income inequality in Slovakia after the transition and the break-up with the Czech Republic. The budget survey used excludes households headed by pensioners that include economically active persons and households headed by the unemployed.

${ }_{28}$ At the same time, there are new problems that have appeared, compared to pre-transition countries. One is increasing refusal rates, particularly among richer households, and the other is that earnings are no longer validated using enterprise records (Milanovic, 1998).

${ }^{29}$ Moreover, no adjustments are made for economies of scale or adult equivalents, but all data are presented in per capita magnitudes. In pre-transition countries, this can be justified since housing, the most important source of economies of scale, was heavily subsidized and thus played an unimportant role in the expenditure patterns of households. This heavy subsidy for housing is still present in a number of countries, though much less so than previously. See Fleming and Mickleright (2000) and Atkinson and Mickleright (1992) for a discussion.

${ }^{30}$ For more details on the data problems, see also Appendix 1 in Milanovic (1998).

${ }^{31}$ This is particularly the case for the countries where the surveys have been reformed or new instruments developed.
} 
benchmark years chosen, this will counter the bias (mentioned above) of an apparent overestimate in the increase in inequality in several transition countries.

For comparable developing countries, we rely on the well-known Deininger and Squire data set (1996), which provides information about Gini coefficients and quintiles shares for more than 100 countries at irregular intervals. Unfortunately, the data are not based on consistent definitions of the income used and the economic unit considered and have been criticized for that and other short-comings by Atkinson and Brandolini (1999). In the sensitivity analysis, we will address this issue and use a regression-based approach to generate a more consistent data source. This will also allow us to address the problem of different income definitions in pre- and posttransition countries.

Due to the fact, that data on income distribution did not exactly match our years chosen for the analysis, we had to make some adjustments. In case there is no Gini coefficient for the particular point in time, we used the nearest available data for our calculations. Table 1 shows, how we have connected the data on per capita income and inequality. ${ }^{32}$

The international analysis we will perform for 1980, 1988, and 1995. The first two data points represent the pre-transition situation and 1995 the post-transition situation. For the intertemporal analysis in transition countries, we examine mainly the period between 1988 and 1995.

\section{International Analysis}

Table 2 presents the results for 1980 . The analysis is restricted to 18 countries, among them only three (future) transition countries, Bulgaria, Hungary, and Poland. The first three columns report per capita incomes, using exchange rates, and two estimates of PPP, respectively. Comparing column one with the following two shows large differences which are due to overand undervalued exchange rates. This discrepancy is larger among poorer countries, related to the systematic undervaluation of the non-traded sectors in poor countries (Summers and Heston, 1991). Column two illustrates the PPP-adjusted per capita incomes provided by the Penn World Tables 5.6 (NBER, 2000), and column three the PPP-adjusted mean incomes published by the World Development Indicators (World Bank, 1999). The comparison suggests that the PPP adjustment is subject to a considerable margin of error. While the two PPP adjustments lead to similar results in about a third of the countries they differ, sometimes considerably, in the other two-thirds. China, Indonesia, Thailand, Malaysia, and Bulgaria look a lot richer in the PPP adjustment from the Penn World Tables than in the adjustment done by the World Bank, while the reverse appears to be the case for most Latin American countries, the Philippines, and Portugal. As one can see, the determination of international prices to adjust for different purchasing powers are sensitive to the methods used and therefore the rankings according to these measures differ.

The next two columns show the Atkinson measure with $\varepsilon=1$ and the Sen measure, both exhibiting a comparatively 'mild' well-being penalty for inequality. The last two are the Atkinson with $\varepsilon=2$ and the Dagum measures with a more heavy implied well-being penalty for inequality.

Well-being, as estimated by our measures, falls drastically when considering inequality. Using the Sen or Atkinson $\varepsilon=1$ measure, well-being falls by about $6-58 \%$ and by up to $70 \%$ (in Brazil and Mexico) in the Dagum and Atkinson $(\varepsilon=2)$ measure. Existing inequality thus leads to fairly major reductions in measured well-being in all the countries considered. As a result of low

\footnotetext{
${ }^{32}$ In nearly all cases, we use the exact year for the income estimate under the (implicit) assumption that changes in income distribution between adjacent years are typically smaller than changes in mean income.
} 
income inequality, the three Eastern European countries attract by far the smallest penalty for inequality of all countries considered. Well-being is reduced by less than $10 \%$ in the Atkinson $(\varepsilon=1)$ and 'only' up to $40 \%$ in the Dagum measure. As a result, the ranking of the Eastern European countries improves considerably. For example, Bulgaria has rank 12 in the PPP adjusted income per capita measure (column three) and improves to rank 7 in the Atkinson $(\varepsilon=2)$ and Dagum measures.

In 1980, Spain has the highest rank in most measures, and nothing can prevent China from being at the bottom of the list for all indicators. Nevertheless, there are also a number of interesting rank reversals. For example, low inequality Bulgaria and high inequality Brazil trade places between the income measures and the broader well-being measures. In the three income measures, Brazil is up to 11 ranks ahead; while in the Atkinson $(\varepsilon=2)$ and Dagum measure, Bulgaria is four and three ranks ahead, respectively. This reversal indicates that the well-being effect of more than 50\% higher PPP adjusted per capita income (column 3) in Brazil is more than off-set by the much higher inequality. Put differently, the more equal distribution in Bulgaria in 1980 achieves higher levels of well-being as measured by these indicators than the $50 \%$ higher per capita incomes in Brazil. There are similar reversals between low inequality Hungary and high inequality Mexico and low inequality Poland and high inequality Costa Rica.

Table 3 shows our rankings for 33 countries in 1988. The list now includes more transition countries, among them many of the successor states (to be) of the former Soviet Union. This year becomes the pre-transition benchmark for assessment of the impact of transition. Again, there are large differences between exchange rate based estimates of real incomes and PPP estimates, with the discrepancy being largest among poorer countries. Considering inequality continues to reduce well-being drastically. Once again, Brazil loses most: Well-being using the Dagum measure is $72 \%$ below the level it would be if its per capita income were equally distributed! As before, the penalties in Eastern Europe are much smaller than elsewhere due to their lower inequality. As a result, Eastern Europe and the successor states of the Soviet Union all improve their rank when inequality is considered. In the income measure, the worst-off eight include three socialist countries; in the Dagum measure, there is none.

While Spain remains on top and China at the bottom in all measures, some more dramatic reversals in rank occur. For example, Panama is seven ranks ahead of Kyrgyz Republic in the income measure, but is nine and twelve ranks behind Kyrgyz Republic in the Dagum and Atkinson $(\varepsilon=2)$ measures, respectively. Unequal Brazil trades places with more equal Moldova, and, on the upper end, Portugal gets surpassed by countries like the Czech Republic, and Slovakia when the well-being measures include the distribution of income as well.

The pattern of inequality in the socialist countries also appears to be different from the pattern of inequality observed elsewhere. Table 5 shows that the socialist countries, while having lower inequality throughout the income distribution, have particularly high levels of income shares accruing to the poorest quintile. They are close to, and often above, $10 \%$ while they are much lower in comparable countries. In contrast, the income shares among middle-income groups do not differ so much. The comparison between Spain, on the one hand, and Russia, Bulgaria, and Ukraine on the other is instructive. Despite having similar Gini coefficients, the socialist countries have higher income shares among the poorest quintile. At the same time, they also have higher income shares accruing to the richest than in Spain, while the middle income groups do worse. Since, as discussed above, the Gini-based measures metes out a higher penalty for inequality in the middle income groups, while the Atkinson measure places the largest weight on income inequality among the poorest groups and the least on income inequality among richer groups (and thus obeys 'transfer sensitivity'), we would expect that the socialist countries do relatively better with the Atkinson measures than the Gini-based measures. This is indeed the 
case as shown in Tables 3 and 5. In Table 3 we see that in all socialist countries the inequalityadjusted income using the Atkinson $(\varepsilon=2)$ measure is much higher than in the Sen measure; in contrast, in all Latin American and some Asian countries the reverse is the case. As a result, the socialist countries do particularly well in the ranking using the Atkinson $(\varepsilon=2)$ measure, while the Latin American countries, with their puny income shares accruing to the poorest, fare particularly badly (see also Figure 2).

This difference can also be seen in Table 5 where we simply subtract the inequalityadjusted income shares (the inequality-adjusted income as a share of the unadjusted per capita income as reported in columns 5 and 6 in Table 3) using the Atkinson $(\varepsilon=2)$ and the Dagum measure. In socialist countries this difference is always larger than 20 percentage points suggesting that well-being in these countries appears a lot larger using the Atkinson measure than a Gini-based measure such as the Dagum measure. This is to say that the Dagum measure suggests that well-being in socialist countries is reduced by more than 20 percentage points more due to the prevailing inequality than the Atkinson measure would imply. In most other countries this difference is much smaller. In some Latin American countries, it is negligible. These are considerably differences indeed.

Thus our impression of well-being in pre-transition socialist countries depends to a considerable extent on whether we believe transfer sensitivity, which attaches a higher weight to transfers among the poor than to equal-sized transfers among the rich, is a desirable property or not. If we do, which most observers support (e.g. Atkinson, 1970; Blackorby and Donaldson, 1978), we use the Atkinson measures and reward the socialist countries for their high income shares accruing to the poorest; if we do not, as supported by Dagum (1990) and Sen (1997), we punish them for the comparatively low income shares among middle income groups. Thus these seemingly arcane and technical differences in assumptions underlying the different well-being measures do play a significant role in the comparative assessment of well-being in socialist countries.

Table 4 examines the same 33 countries for 1995, our benchmark year for countries having undergone a (sometimes still incomplete) transition to a market economy. The inequality-adjusted measures continue to be much lower than the income measure suggesting that inequality continues to have a big impact on well-being. Brazil and Colombia continue to suffer from the largest reductions in well-being which are also now larger than previously, suggesting not only high but worsening inequality.

Regarding transition economies, several important observations emerge. First, due to sharply declining incomes in many transition countries, and increasing incomes elsewhere, most transition countries slip in the income ranking. While six of the ten richest (in terms of PPP income) economies in 1988 were pre-transition socialist countries, only three remain in the top 10 in 1995. Conversely, instead of two there are now six transition countries among the poorest ten. This slippage in rank is largest for the successor states of the Soviet Union. Russia slips ten ranks, Ukraine eight, Turkmenistan eight, Kazakhstan twelve ranks. In contrast, the Central European countries witness the least worsening in ranks.

Second, it is no longer invariably the case that the transition countries improve their rank once inequality is considered. While this is still the case for the majority of Central, Eastern, South-Eastern European countries, and the Baltic Republics, it is no longer the case for many successor states of the former Soviet Union. Due to sharply increased inequality, Russia now worsens its rank, once inequality is considered. The same is true for the Ukraine, and the Kyrgyz Republic, while some of the other ex-Soviet States now merely maintain their rank once inequality is considered. Thus we find that a consideration of inequality continues to improve the impression of relative well-being in all transition countries with the exception of several of the 
former Soviet States. Moreover, due to rising inequality virtually everywhere, the improvement in rank is now less than previously.

Third, as a result of falling incomes and rising inequality, the rank reversals between transition countries and comparable countries have changed considerably. While inequality in transition countries is still far below the levels of inequality in some developing countries, notably those from Latin America, rising inequality in transition countries ensures that the differences in rank are no longer as large as before. Instead of being seven ranks ahead of the Kyrgyz Republic in 1988 in per capita incomes, Panama is now 23 ranks ahead. This still gets reduced, once inequality is considered, but Panama remains fifteen ranks, and six ranks ahead in the Dagum and Atkinson ( $\varepsilon=2$ ) measure (see also Figure 2). China also manages to surpass a number of transition countries for the first time in 1995, indicating that the transition there appears to have been much more successful in increasing incomes and in stemming the rise in inequality. Similarly, Brazil remains far ahead of Moldova, even if inequality is considered, and the Czech Republic and Slovakia are no longer able to surpass Portugal even if inequality is considered. Only Slovenia which has managed to surpass its pre-transition income by a considerable margin (see Figure 1) and has experienced a comparatively small increase in inequality, is able to surpass Portugal and occupy rank 2 in the Dagum and Atkinson $(\varepsilon=2)$ measure.

Fourth, difference in the kind of inequality between some transition countries and comparable countries is also now much reduced. Table 5 shows that a considerably share of the increase in inequality has appeared in the form of declining income shares to the poorest quintile, whose income shares in several transition countries are now similar to non-transition countries. As a result, comparisons of Tables 4 and 5 show that the many transition countries with rising inequality are experiencing larger reductions when the Atkinson measure is used compared to when the Gini-based measures are used. For example, in the Ukraine using the Atkinson $(\varepsilon=2)$, the inequality-adjusted share is reduced from $85.5 \%$ to $51.4 \%$ between 1988 and 1995; in the Dagum measure, the reduction is considerably smaller, from $62.2 \%$ to $35.7 \%$. As a result, the difference between the Atkinson $(\varepsilon=2)$ and the Dagum measure is no longer invariably much larger in transition countries than elsewhere. Indeed, there are a number of countries where the difference is now similar to non-transition countries (see Table 3). At the same time, the differences remain large in the Central European countries where there was little increase in inequality and the income shares of the poorest quintile remained above $10 \%$.

It is hard to summarize the many particular findings from this discussion. But a few points are worth noting. First, consideration of inequality has a large impact on well-being. Well-being falls by $5-75 \%$ once we consider inequality. Second, large differences in inequality between countries lead to very large changes in rank. Pre-transition countries invariably improved their rank while many comparable developing countries experienced a corresponding fall in rank. The income losses associated with the transition has led to a worsening in well-being ranking of many transition countries. At the same time, worsening inequality in some countries has reduced their improvement in rank in the inequality-adjusted measures. But this not true for all transition countries. Figure 2 nicely summarizes these findings by making several bilateral comparisons of well-being rankings in 1988 and 1995. The Ukraine-Indonesia comparison shows how plummeting incomes and rising inequality can worsen the comparison with a country which had rapidly rising incomes and stable inequality. In 1988, Ukraine had higher income levels; considering inequality increased the distance to Indonesia further. In 1995, Ukraine has a much lower income rank, and the difference becomes even larger when inequality is considered. ${ }^{33}$ Similar changes occur in the comparison between Panama and Kyrgyz Republic.

\footnotetext{
${ }^{33}$ The improvement in Indonesia in the inequality-adjusted measures is not due to falling inequality in Indonesia, but due to rising inequality in all the transition countries.
} 
On the other hand, the comparisons between Poland and Brazil show that despite falling incomes, Poland manages to have a higher rank in the inequality-adjusted measures in 1995 since its inequality has risen by much less and remains far below Brazil's. The same holds for Romania and Thailand. ${ }^{34}$ Lastly, in the countries where inequality has worsened considerably, the nature of inequality has also changed. In particular, the poor are hardest hit by rising inequality and the countries therefore experience larger declines in the Atkinson measures than in the Gini-based measures.

\section{Sensitivity Analysis}

In the sensitivity analysis, we consider to what extent our results are driven by inconsistencies in the data on income inequality and the particular data series used. To assess to what extent these findings are due to peculiarities and inconsistencies in the income definition of the datasets used, we examine to what extent the rankings are affected by replacing the data with regression-based adjusted Gini coefficients ${ }^{35}$. We present some examples of such a sensitivity analysis.

First, we regress the reported Gini coefficients on the income definition (expenditure, net income, unknown income, or gross income, the excluded category), and the reference unit considered (unknown, household, or person, the excluded category). Following suggestions from Atkinson and Brandolini (1999), we do not restrict the regression to the 'accept' series by the Deininger and Squire dataset but also include data labeled as cs (no consistent source) and ps (primary source unknown). This enables us to get several observations per country at the same time, which should improve our ability to identify the reference unit and income definition effects. ${ }^{36}$ Regression 1 in Table 6 shows that indeed the income definition and the choice of reference unit do matter. Expenditure-based and net-income or equivalized Gini coefficients are typically lower, while household-based Ginis appear to be higher. ${ }^{37}$ The interaction term 'net income and OECD countries' in the second regression shows that the difference between gross and net income is largely a phenomenon of OECD countries, as one would expect (Atkinson and Brandolini, 1999). We then adjust the Gini coefficients based on the coefficients from the second regression and thereby base all these adjusted Ginis on disposable income per person. This way we should have dealt with the most glaring inconsistencies of the data from Deininger and Squire, although further adjustments are surely possible (Atkinson and Brandolini, 1999).

How do the results change if one uses these adjusted Ginis? Table 7 shows that generally the results do not change greatly. Using the Sen measure, the vast majority of rankings remains the same or change only by one; using the Dagum measure, there are variations that are more significant. However, there is more persistence than change. In 1995, the year when most changes occur due to the adjusted Ginis, only four (of 33 countries) ranks change by more than one position. ${ }^{38}$ Moreover, most of the dramatic rank reversals discussed earlier still hold, although one or two are slightly less dramatic than previously.

\footnotetext{
${ }^{34}$ Romania and Poland both improve in the ranking between 1988 and 1995, no matter what indicator is used. This is not due to improving well-being here, but smaller declines in well-being in these two countries compared to other transition countries.

${ }^{35}$ For the regression we do not only rely on the Gini coefficients from our sample, but include all data on income distribution available by the two Deininger and Squire datasets as well as from The World Income Inequality Database, subject to the selection criteria described above (Wider, 1999).

${ }^{36} \mathrm{We}$ include dummies for PS and CS to ensure that the mixing of these sets does not cause further distortions.

${ }^{37}$ The somewhat surprising result about household-based Ginis was also found by Lundberg and Squire (1999). Note that the regressions here have considerably higher explanatory power (as measured by the R-squared) as the ones used by Dollar and Kraay (2000) and Lundberg and Squire (1999).

${ }^{38}$ The most significant change is a worsening of 4 ranks by Mexico.
} 
Second, we also looked for data on income inequality from other sources and compared them to the once we have used. Appendix 2 gives an overview ${ }^{39}$. For the pre-transition period, we found data in Atkinson, Micklewright (1992) and Flemming and Mickleright (2000) with a similar income concept used. According to these data sources, inequality has been slightly higher in most transition countries. The differences to the Milanovic data are the largest for the Baltic States. Nevertheless, the differences remain modest and both data sets suggest that income inequality in socialist countries was considerably below the levels prevailing in the countries we are comparing them with.

Considering the post-transition period we can contrast the data we used with another expenditure-based measure also taken from Milanovic (1998) and one different data source, (Flemming, Micklewright, 2000) respectively. For both 'datasets', there is no such clear tendency as in the pre-transition period that all Gini coefficients provided are higher (or lower) compared to the data used in our analysis. Using expenditures per capita, there are only minor differences comparing the two different income concepts, except for the Kyrgyz Republic. Here the Gini coefficient based on expenditures is 12 percentage points below that using income data. Applying this lower inequality measure would somewhat improve the ranking of the Kyrgyz Republic in our inequality-adjusted measures. It would not change the result of a dramatic worsening in rank, however.

The few data points provided by Flemming and Micklewright (2000) are in general also similar to the once we have used. Only for Russia, the Gini coefficient is significantly lower, namely 10 percentage points (and up to 12 percentage points compared to the expenditure based coefficient). But this lower Gini-coefficient is based a problematic data source, the old budget survey that suffered from many deficiencies. When examining the data source most used for inequality assessments in post-transition Russia (the Russian Longitudinal Monitoring Survey), this Gini varies from 0.43 in 1992 and 0.48 in 1996, quite similar to the figure we used (which is based on that survey, see Milanovic, 1998). Moreover, despite these differences, both data sources point to a dramatic worsening of inequality in Russia in the early 1990s.

This sensitivity analysis suggests that few of the basic results on the large absolute impact of inequality and the change in ranks as a result of it reported are meaningfully affected by using different data sets. ${ }^{40}$ In particular, it remains the case that the combination of falling incomes and rising inequality leads to a dramatic worsening of rank for most transition countries, particularly among the successor states of the Soviet Union.

\section{Comparisons Across Time}

The discussion in section 5 has already shown that in many transition countries, inequality has changed considerably for the worse. In contrast, among non-transition countries, it appears that there is also a great deal of stability in inequality measures. ${ }^{41}$ Most countries seem to either improve or worsen in rank at a point in time when inequality is considered, with this relationship not changing much over time. Thus for most non-transition countries, the inequality-adjusted measures of well-being will not differ greatly from the growth rate in per-capita incomes.

In transition countries, however, income growth seriously biases our view of changes in well-being. Per capita income losses in the first few years (from 1988 to 1995) already amount to

\footnotetext{
${ }^{39}$ First, we also included data for transition countries from the Deininger and Squire datasets (1996, 1998), but they mostly used the data provided by Milanovic.

40 There is, however, some support for Milanovic's (1998) contention that inequality was slightly understated in a number of pre-transition countries and the subsequent increase has thus been overstated.

${ }^{41}$ See Deininger and Squire (1998) and Lundberg and Squire (1999).
} 
between 5\% in Poland to some 55\% in Ukraine and Turkmenistan. But rising inequality ensures that these losses are distributed very unevenly among the population. Figure 3 shows dramatic differences in income growth by decile in the four countries selected. In Russia, the poorest decile suffers from a $70 \%$ drop in real incomes, while the richest decile gains nearly $50 \%$. Similar differences exist in the Ukraine although here all deciles lose, but the rich much less than the poor. In Poland, a country with a lower income loss, the differences in income losses among the declies are much smaller; in Slovakia, the data suggest a slight improvement in income inequality, with the poorest losing less than other groups.

Using our measures, this rising inequality further reduces well-being, in some countries by considerably amounts. Figure 4 shows the combined effect of income drops and rising inequality on our inequality-adjusted well-being measures. For example, the already severe income losses in Russia of some $43 \%$ translate, combined with the rising inequality, to well-being losses of 55$68 \%$, depending on the measure chosen. In the Ukraine, the income loss of 55\% combines with rising inequality to a well-being loss of $68-75 \%$. Similar dramatic differences between income losses and well-being losses exist in the Moldova, Estonia, Latvia and Kyrgyz Republic. Once again, we see that the Central European countries, things are not nearly as bad. Income losses are smaller, and the rise in inequality was more modest. As a result, well-being losses are not so different from income losses in Hungary, Poland, the Czech Republic, or Slovenia. Slovakia is the only country where our impression of changes in well-being changes for the better once the (slightly) declining inequality is included. ${ }^{42}$

In fact, there appears to be an interesting correlation between the per capita income losses and the changes in inequality. In Figure 5 it appears that the countries with the smallest income losses also experienced the smallest increase in inequality; conversely, those with the largest income losses experienced the largest increase in the Gini coefficient. As a result, an incorporation of inequality magnifies the already large differences in per capita growth rates between countries.

This correlation might be related to progress in transition itself. The EBRD's transition index (EBRD, 2000) suggests that the countries where transition has been fastest, income losses have been least (see Table 8). A fortiori, this would also mean that the countries where transition has been fastest, the rise in inequality has been the smallest. There could be causal linkages here. In particular, slow transition might mean that the transition process has been captured and delayed by old elites who are able to slow the move towards a competitive market economy and enrich themselves in the process. In contrast, the poor lose out as they depend on state resources (pensions, social benefits, etc) that are falling and becoming more unequal in countries where transition is slow and the resulting ability of the state to get a secure revenue base from taxation low (see Flemming and Micklewright, 2000; Milanovic, 1989). ${ }^{43}$

But this correlation is far from perfect. For example, in the Baltic Republics, the transition index suggests good progress, while income losses have been very severe and the rise in inequality has also been large. Similarly, in Belarus and the Central Asian Republics show least progress in transition, but they do not have the largest income losses nor, on average, the fastest

\footnotetext{
${ }^{42}$ While incomes have grown somewhat in some countries between 1993 and 1999, this has been insufficient to counteract the effect of the previously falling incomes and the increasing inequality on well-being.

${ }^{43}$ For example, insider privatization, little progress in restructuring and competition, combined with the inability of the state to raise sufficient revenue to pay for pensions and other social commitments appear to have lead to a combination of poor progress in transition, large income losses, and large increases in income inequality in Russia. As a result of these developments, the wage distribution became a lot more unequal and highly dependent on the sector of the economy, non-wage private income made up a sharply increasing share of total income, and social transfers became much more unequal. For a discussion, see Milanovic (1998) and Flemming and Micklewright (2000).
} 
increases in inequality. ${ }^{44}$ It is beyond the scope of this paper to investigate these issue in detail. ${ }^{45}$ The large differences in the experience of transition countries suggest, however, that large income losses and large increases in inequality is not the inevitable fate of transition economies. Apparently, there is considerable scope for economic policy to influence both developments, an issue that deserves further investigation. In particular, the apparent linkage between income loss and inequality increases deserve close scrutiny as this have a compound effect on well-being.

The economic misery that has accompanied the transition appears much deeper once the rising inequality is factored in. In eight countries, well-being has fallen by over $40 \%$. Social indicators of well-being support this impression of a general deterioration in economic conditions (see also Klasen, 1994a; UNICEF, 1993; UNDP, 1996). Compared to a rising trend elsewhere in the world and in comparable middle-income countries, Table 8 shows that life expectancy dropped for both males and females in Kazakhstan, Russia and Ukraine, while it fell only for males in the Baltic Republics. But the deteriorations appear smaller than one might expect given the disastrous drops in our economic well-being indicators. Also, they do not extend to all countries; in most Central European countries, life expectancy continued to rise, albeit at a slower pace than previously.

With regard to under five mortality rates, the picture looks somewhat brighter. For countries with data available in 1989 as well as 1998, Latvia is the only country, in which the situation has worsened. Education indicators, on the other hand, suggest a considerably deterioration. Compared to a rising trend elsewhere, secondary enrolment rates have dropped in nearly all transition countries, in some countries by more than $20 \%$.

When it comes to indicators of political and civil liberties, however, the story looks very different. Now most transition countries show large improvements in these indicators, which run counter to the income, inequality, and human development indicators. While four transition countries (Belarus and several Central Asian states) remain unfree, 10 are now considered free, and another four partly free.

Clearly, there is a close correlation between regress in well-being and most social indicators of well-being. The fact that the latter have deteriorated somewhat less than the former might point to the success of efforts to protect social services in most countries, as well as to nonlinearities in the relationship between economic well-being and social measures of well-being. ${ }^{46}$ While the economic assessment of the transformation process looks generally quite bleak (but

\footnotetext{
${ }^{44}$ Milanovic (1998) classifies countries by the amount of compensation they provide to people negatively affected by the transition process. He defines 'non-compensators' as countries where losses in the share of wage income are not offset by increases in social transfers, 'compensators' where a fair amount of 'off-set' has taken place, and 'populists' where all sources of population income increased as a share of GDP. The first group includes the Czech Republic, Estonia, Moldova, Romania, Russia, Slovakia, and Ukraine, the second group includes Belarus, Bulgaria, Latvia, and Lithuania, and the third group is comprised of Hungary, Poland, and Slovenia. He finds that the increase in Gini was largest among the non-compensators but this is entirely dependent on the inclusion of Russia and Ukraine (Milanovic, 1998). It appears that his classification is much more heterogeneous than the correlation between income growth and inequality increases presented in Figure 5.

${ }^{45}$ One apparent regularity appearing in the data is that there might be an inverse U-shape in the relationship between transition and inequality increase. Those countries which have hardly begun to undertake a transition, such as Belarus and some of the Central Asian Republics, have, by maintaining the status quo, been able to reduce the increase in inequality; in some countries, this apparently came at the expense of large drops in income. Those that have undertaken a slow and incomplete transition (e.g. Russia, Ukraine) have suffered the large income losses and the biggest increases in inequality, while those that have undertaken a rapid transition (e.g. Poland, Hungary, Czech Republic) have managed to keep income losses and increases in inequality fairly low. This would be interesting to explore further.

${ }^{46}$ For example, there appears to be a logarithmic relationship between per capita incomes and life expectancy which would suggest that at fairly high levels of per capita incomes, even a sharp reduction in income will only reduce life expectancy by a few years. See Ray (1998).
} 
varies greatly according to country), the indicators of political and civil rights show that the political dimension of the transformation was and remains, by and large, a large success in most transition countries (see also Sen, 1991).

\section{Conclusion}

In this paper, we investigated how inequality-adjusted indicators of well-being would change our impression of well-being in transition countries before and during the transition process. We did this by comparing transition countries with comparable non-transition countries and investigated intertemporal changes in well-being in transition countries. The main results of our investigation are the following.

First, it is theoretically justified and empirically important to adjust incomes by the amount of inequality to arrive at more meaningful measures of well-being. Applying these measures indicates that inequality can have a sizeable impact on well-being.

Second, combined with their moderate income levels, the comparatively low inequality in socialist countries ensured fairly high levels of well-being. In the transition process, well-being has been eroded by falling incomes and by rising inequality. This has worsened the comparative position of transition countries.

Third, low inequality in socialist countries was characterized by particularly high income shares of the poorest quintile. The transition has brought disproportionate losses to this group in most countries so that the nature of inequality in many transition countries is now more similar to non-transition states.

Fourth, there are great differences in the performance of transition countries. In particular, there appears to be a close correlation between income losses and increases in inequality. As a result, an inclusion of inequality accentuates the differences in well-being between the countries with comparatively small income losses and those with large ones. This suggests that neither the large income losses nor the huge increase in inequality experienced in some countries were inevitable features of the transition process. Some countries managed to transform themselves with minor income losses and little increase in inequality. The reasons for this different performance should be investigated further, given its huge implication for well-being.

Finally, it remains the case that the political transformation in most of the former socialist countries has been a great success. Before the transformation, political and civil liberties were low and they have improved hugely in the last ten years. While the political failings of the socialist countries were considerable and have been overcome in most states, the economic failings of the socialist economies were smaller than previously thought, especially if one includes inequality in an assessment of well-being. It is also the case that the ten years of economic transformation have not been able to restore economic well-being as measured by our indicators to the levels they enjoyed at the end of the socialist period. 
Table 1: The Matching of Income and Inequality Data, 1980-1995

\begin{tabular}{|c|c|c|c|}
\hline Country & $1980-$ Gini $^{\text {a }}$ & 1988 - Gini & 1995 - Gini \\
\hline Bulgaria & $1980(25.0)$ & $1989(23.3)^{\mathrm{c}}$ & $1993(34.3)^{\mathrm{c}}$ \\
\hline Belarus & - & $1988(22.8)^{\mathrm{c}}$ & $1995(28.4)^{\mathrm{c}}$ \\
\hline Brazil & $1980(57.8)$ & $1987(56.2)$ & $1995(60.1)^{b}$ \\
\hline China & $1980(32.0)$ & $1988(34.9)$ & $1992(37.8)$ \\
\hline Colombia & $1978(54.5)$ & $1988(51.2)$ & $1995(57.2)^{b}$ \\
\hline Costar Rica & $1981(47.5)$ & $1986(42.0)$ & $1996(47.0)^{b}$ \\
\hline Czech Republic & - & $1988(19.4)^{c}$ & $1993(26.6)^{c}$ \\
\hline Spain & $1980(26.8)$ & $1988(24.4)$ & $1990(32.5)^{b}$ \\
\hline Estonia & - & $1988(23.0)^{\mathrm{c}}$ & $1995(35.4)^{\mathrm{c}}$ \\
\hline Hungary & $1982(21.0)$ & $1987(21.0)^{\mathrm{c}}$ & $1993(22.6)^{\mathrm{c}}$ \\
\hline Indonesia & $1980(35.6)$ & $1987(32.0)$ & $1995(34.2)^{b}$ \\
\hline Jamaica & $1988(43.2)$ & $1988(43.2)$ & 1993 (37.9) \\
\hline Kazakhstan & - & $1988(25.7)^{c}$ & $1993(32.7)^{\mathrm{c}}$ \\
\hline Kyrgyz Republic & - & $1988(26.0)^{c}$ & $1993(55.3)^{\mathrm{c}}$ \\
\hline Lithuania & - & $1988(22.5)^{c}$ & $1994(37.3)^{\mathrm{c}}$ \\
\hline Latvia & - & $1988(22.5)^{\mathrm{c}}$ & $1995(31.0)^{\mathrm{c}}$ \\
\hline Moldova & - & $1988(24.1)^{\mathrm{c}}$ & $1993(36.5)^{\mathrm{c}}$ \\
\hline Mexico & $1984(50.6)$ & $1989(55.0)$ & $1992(50.3)$ \\
\hline Malaysia & $1979(51.0)$ & $1989(48.4)$ & $1995(48.5)^{b}$ \\
\hline Panama & $1980(47.5)$ & $1989(56.5)$ & $1991(56.8)^{b}$ \\
\hline Peru & $1981(49.3)$ & $1986(42.8)$ & $1994(44.9)$ \\
\hline Philippines & $1985(46.1)$ & $1988(45.7)$ & $1991(43.8)^{b}$ \\
\hline Poland & $1980(24.9)$ & $1987(25.6)^{c}$ & $1993(28.4)^{\mathrm{c}}$ \\
\hline Portugal & $1980(36.8)$ & $1990(36.8)$ & $1991(35.6)$ \\
\hline Romania & - & $1989(23.3)^{c}$ & $1994(28.6)^{c}$ \\
\hline Russia & - & $1988(23.8)^{c}$ & $1993(48.0)^{\mathrm{c}}$ \\
\hline Slovakia & - & $1988(19.5)^{\mathrm{c}}$ & $1993(18.3)^{\mathrm{c}}$ \\
\hline Slovenia & - & $1987(21.5)^{c}$ & $1993(25.1)^{\mathrm{c}}$ \\
\hline Thailand & $1981(43.1)$ & $1988(47.4)$ & $1992(51.5)$ \\
\hline Turkmenistan & - & $1988(26.4)^{c}$ & $1993(35.8)^{\mathrm{c}}$ \\
\hline Ukraine & - & $1988(23.3)^{c}$ & $1995(47.4)^{\mathrm{c}}$ \\
\hline Uzbekistan & - & $1989(28.2)^{c}$ & $1993(33.3)^{\mathrm{c}}$ \\
\hline Venezuela & $1981(42.8)$ & $1987(45.2)$ & $1995(46.8)^{b}$ \\
\hline Total & 18 & 33 & 33 \\
\hline
\end{tabular}

Gini coefficients are in parentheses.

a: Gini coefficients for 1980 and those not otherwise marked are taken from Deininger-Squire dataset (1996). Income concept mostly gross income per person.

b: Gini coefficient from updated Deininger-Squire (1998). Income concept mostly gross income per person.

': Gini coefficient from Milanovic (1998). Income concept for the year 1988 is mostly gross per capita income, for 1995 disposable income per capita. 
Table 2: Welfare measures 1980

\begin{tabular}{|c|c|c|c|c|c|c|c|c|c|c|c|c|c|c|}
\hline \multirow{2}{*}{$\begin{array}{c}\text { Rank } \\
18\end{array}$} & \multicolumn{2}{|c|}{ 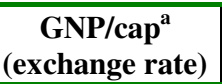 } & \multicolumn{2}{|c|}{$\begin{array}{c}\text { GNP/cap }^{b} \\
\text { (PPP) }\end{array}$} & \multicolumn{2}{|c|}{$\begin{array}{c}\text { GNP/cap }^{\mathrm{c}} \\
\text { (PPP) }\end{array}$} & \multicolumn{2}{|c|}{$\begin{array}{c}\text { Atkinson } \\
(\varepsilon=1)^{d}\end{array}$} & \multicolumn{2}{|c|}{$\operatorname{Sen}^{e}$} & \multicolumn{2}{|c|}{ Atkinson $(\varepsilon=2)^{\mathrm{f}}$} & \multicolumn{2}{|c|}{ Dagum $^{\text {g }}$} \\
\hline & 170 & CHN & 1339 & CHN & 816 & $\mathrm{CHN}$ & $87.3 \%$ & CHN & $68.0 \%$ & CHN & $75.8 \%$ & CHN & $51.5 \%$ & CHN \\
\hline 17 & 481 & IDN & & IDN & 1542 & IDN & & IDN & & IDN & $1.4 \%$ & IDN & $7.5 \%$ & IDN \\
\hline 16 & 1115 & THA & 2575 & PHL & 2666 & THA & $71.8 \%$ & THA & $56.9 \%$ & THA & $52.4 \%$ & THA & $39.8 \%$ & THA \\
\hline 15 & 1164 & PHL & 2937 & JAM & 3047 & JAM & $75.8 \%$ & JAM & $56.8 \%$ & JAM & $59.0 \%$ & JAM & $39.7 \%$ & JAM \\
\hline 14 & 1308 & BGR & 2978 & THA & 3790 & PHL & $66.6 \%$ & MYS & $49.0 \%$ & MYS & $46.2 \%$ & MYS & $32.5 \%$ & MYS \\
\hline 13 & 1347 & JAM & 3812 & PER & 4099 & MYS & 73. & PHL & $53.9 \%$ & PHL & 56 & PHL & 36. & PHL \\
\hline 12 & 16 & COL & 40 & $\mathrm{COL}$ & 4117 & BGR & 67. & PER & $50.7 \%$ & PER & 40 & $\mathrm{COL}$ & 29 & $\mathrm{COL}$ \\
\hline 11 & & MYS & 45 & PAN & & PER & 62 & $\mathrm{COL}$ & $45.5 \%$ & $\mathrm{COL}$ & & BRA & 33. & PER \\
\hline 10 & 7 & CRI & 4834 & CRI & 5368 & $\mathrm{COL}$ & $58.0 \%$ & BRA & $42.2 \%$ & BRA & $52.4 \%$ & PER & $26.8 \%$ & BRA \\
\hline 9 & 97 & PAN & 5029 & MYS & 5658 & POL & $92.0 \%$ & BGR & $75.0 \%$ & BGR & & CRI & 35 & PAN \\
\hline 8 & & PER & 5299 & BGR & 5967 & PAN & $67.8 \%$ & CRI & $52.5 \%$ & PAN & $50.0 \%$ & PAN & $35.6 \%$ & CRI \\
\hline 7 & 2909 & POL & 5642 & BRA & 6057 & CRI & $69.7 \%$ & PAN & $52.5 \%$ & CRI & $84.5 \%$ & BGR & $60.0 \%$ & BGR \\
\hline 6 & 3171 & MEX & 5834 & POL & 6456 & BRA & $91.4 \%$ & POL & $49.4 \%$ & MEX & $47.9 \%$ & MEX & $32.8 \%$ & MEX \\
\hline 5 & 4041 & VEN & 64 & HUN & 6601 & HUN & 67.2 & MEX & $75.1 \%$ & POL & $83.6 \%$ & POL & $60.2 \%$ & POL \\
\hline 4 & 4126 & HUN & 66 & PRT & 8070 & MEX & $93.9 \%$ & HUN & $79.0 \%$ & HUN & $63.6 \%$ & PRT & $40.0 \%$ & VEN \\
\hline 3 & 4423 & BRA & 8054 & MEX & 9158 & PRT & $80.4 \%$ & PRT & $63.2 \%$ & PRT & $88.4 \%$ & HUN & $46.2 \%$ & PRT \\
\hline 2 & 6996 & PRT & 10054 & ESP & 10374 & VEN & $75.2 \%$ & VEN & $57.2 \%$ & VEN & $57.3 \%$ & VEN & $65.3 \%$ & HUN \\
\hline 1 & 10427 & ESP & 10166 & VEN & 11462 & ESP & $89.4 \%$ & ESP & $73.2 \%$ & ESP & $79.2 \%$ & ESP & $57.7 \%$ & ESP \\
\hline
\end{tabular}

Country codes are explained in Appendix 1.

a): Data taken from World Bank (1999), measuring GNP/cap, constant 1995 US-Dollars.

b): Data taken from NBER (2000), measuring GNP/cap in constant 1995 international prices (chain index).

c): Data taken from World Bank (1999), measuring GNP/cap, PPP adjusted, constant 1995 US-Dollars.

d): Atkinson measure $(\varepsilon=1)$ computed on the basis of, and expressed as a share of GNP/cap, PPP adjusted (column 3).

e): Sen measure computed on the basis of, and expressed as a share of GNP/cap, PPP adjusted (column 3).

f): Atkinson measure $(\varepsilon=2)$ computed on the basis of, and expressed as a share of GNP/cap, PPP adjusted (column 3). $\mathrm{g})$ : Dagum measure computed on the basis of, and expressed as a share of GNP/cap, PPP adjusted (column 3). 
Table 3: Welfare measures 1988

\begin{tabular}{|c|c|c|c|c|c|c|c|c|c|c|c|c|}
\hline \multirow{2}{*}{$\begin{array}{c}\text { Rank } \\
33\end{array}$} & \multicolumn{2}{|c|}{$\begin{array}{c}\text { GNP/cap }{ }^{\mathrm{a}} \\
\text { (exchange rate) }\end{array}$} & \multicolumn{2}{|c|}{$\begin{array}{c}\text { GNP/cap }^{\mathbf{b}} \\
\text { (PPP) }\end{array}$} & \multicolumn{2}{|c|}{ Atkinson $(\varepsilon=1)^{c}$} & \multicolumn{2}{|c|}{$\operatorname{Sen}^{d}$} & \multicolumn{2}{|c|}{ Atkinson $(\varepsilon=2)^{\mathrm{e}}$} & \multicolumn{2}{|c|}{ Dagum $^{f}$} \\
\hline & 333 & CHN & 1617 & CHN & $83.0 \%$ & CHN & $65.1 \%$ & CHN & $68.2 \%$ & CHN & $48.3 \%$ & CHN \\
\hline 32 & 646 & IDN & 2115 & IDN & $85.5 \%$ & IDN & $68.0 \%$ & IDN & $74.3 \%$ & IDN & $51.5 \%$ & IDN \\
\hline 31 & 1016 & PHL & 3110 & JAM & $75.8 \%$ & JAM & $56.8 \%$ & JAM & $30.8 \%$ & PAN & $39.7 \%$ & JAM \\
\hline 30 & 1328 & UZB & 3322 & MDA $^{g}$ & $72.9 \%$ & PHL & $54.3 \%$ & PHL & $59.0 \%$ & JAM & $37.2 \%$ & PHL \\
\hline 29 & 1345 & JAM & 3372 & PHL & $68.8 \%$ & THA & $52.6 \%$ & THA & $56.0 \%$ & PHL & $35.7 \%$ & THA \\
\hline 28 & 1411 & KGZ & 3546 & UZB & $91.8 \%$ & MDA & $57.2 \%$ & PER & $49.3 \%$ & THA & $27.8 \%$ & PAN \\
\hline 27 & 1596 & MDA $^{g}$ & 3981 & KGZ & $89.2 \%$ & UZB & $43.5 \%$ & PAN & $35.3 \%$ & BRA & $40.1 \%$ & PER \\
\hline 26 & 1635 & THA & 3981 & THA & $56.1 \%$ & PAN & $75.9 \%$ & MDA & $51.8 \%$ & MYS & $34.8 \%$ & MYS \\
\hline 25 & 1702 & COL & 4230 & PER & 76.9 & PER & $51.7 \%$ & MYS & $\%$ & PER & $28.1 \%$ & BRA \\
\hline 24 & 1784 & ROM & 4902 & MYS & $70.1 \%$ & MYS & $71.8 \%$ & UZB & $46.0 \%$ & $\mathrm{COL}$ & $32.3 \%$ & $\mathrm{COL}$ \\
\hline 23 & 1860 & BGR & 4927 & TKM & $90.9 \%$ & KGZ & $48.8 \%$ & $\mathrm{COL}$ & $84.4 \%$ & MDA & $56.0 \%$ & UZB \\
\hline 22 & 2110 & CRI & 5362 & UKR & $57.0 \%$ & BRA & $43.8 \%$ & BRA & $79.8 \%$ & UZB & $61.2 \%$ & MDA \\
\hline 21 & 2121 & TKM & 5549 & CRI & $66.4 \%$ & $\mathrm{COL}$ & $74.0 \%$ & KGZ & $54.8 \%$ & CRI & $29.0 \%$ & MEX \\
\hline 20 & 2226 & KAZ & 5723 & PAN & $74.3 \%$ & CRI & $58.0 \%$ & CRI & $40.9 \%$ & MEX & $40.8 \%$ & CRI \\
\hline 19 & 2247 & PER & 5761 & ROM & 90.7 & TKM & $45.0 \%$ & MEX & $83.4 \%$ & KGZ & $58.7 \%$ & KGZ \\
\hline 18 & 2348 & PAN & 5810 & COL & 61.9 & MEX & $73.6 \%$ & TKM & $83.0 \%$ & TKM & 58. & TKM \\
\hline 17 & 2575 & BLR & 5985 & BGR & $92.5 \%$ & UKR & $76.7 \%$ & UKR & $85.5 \%$ & UKR & $62.2 \%$ & UKR \\
\hline 16 & 2671 & MYS & 6022 & POL & $92.3 \%$ & ROM & $76.7 \%$ & ROM & $5.0 \%$ & ROM & $37.8 \%$ & VEN \\
\hline 15 & 2873 & LTU & 6246 & LTU & 91. & POL & $74.4 \%$ & POL & $\%$ & POL & $59.2 \%$ & POL \\
\hline 14 & 2904 & MEX & 6420 & BLR & 92. & BGR & $76.7 \%$ & BGR & $54.6 \%$ & VEN & $62.2 \%$ & ROM \\
\hline 13 & 3035 & POL & 6507 & KAZ & $93.0 \%$ & LTU & $74.3 \%$ & KAZ & $86.1 \%$ & BGR & $62.2 \%$ & BGR \\
\hline 12 & 3388 & UKR & 6569 & BRA & $90.7 \%$ & KAZ & $77.5 \%$ & LTU & $82.3 \%$ & KAZ & $59.1 \%$ & KAZ \\
\hline 11 & 3563 & VEN & 6756 & LVA & $92.8 \%$ & BLR & $77.2 \%$ & BLR & $86.6 \%$ & LTU & $63.3 \%$ & LTU \\
\hline 10 & 3882 & SVK & 6855 & EST & $92.9 \%$ & LVA & $54.8 \%$ & VEN & $86.1 \%$ & BLR & $62.9 \%$ & BLR \\
\hline 9 & 3895 & RUS $^{\mathrm{g}}$ & 7552 & MEX & $92.3 \%$ & EST & $77.5 \%$ & LVA & $\%$ & LVA & $63.3 \%$ & LVA \\
\hline 8 & 4410 & BRA & 7739 & RUS $^{g}$ & $73.0 \%$ & VEN & $77.0 \%$ & EST & $85.1 \%$ & EST & $62.6 \%$ & EST \\
\hline 7 & 4526 & LVA & 7813 & HUN & $92.0 \%$ & RUS & $76.2 \%$ & RUS & $84.5 \%$ & RUS & $61.6 \%$ & RUS \\
\hline 6 & 4694 & EST & 8871 & SVK & $94.0 \%$ & HUN & $79.0 \%$ & HUN & $88.6 \%$ & HUN & $65.3 \%$ & HUN \\
\hline 5 & 4773 & HUN & 9344 & VEN & $94.7 \%$ & SVK & $80.5 \%$ & SVK & $64.2 \%$ & PRT & $46.2 \%$ & PRT \\
\hline 4 & 5482 & CZE & 11148 & $\mathrm{SVN}^{\mathrm{g}}$ & $80.6 \%$ & PRT & $63.2 \%$ & PRT & $89.8 \%$ & SVK & $67.4 \%$ & SVK \\
\hline 3 & 8272 & $\mathrm{SVN}^{\mathrm{g}}$ & 11459 & PRT & $92.4 \%$ & SVN & $78.5 \%$ & SVN & $85.6 \%$ & SVN & $64.6 \%$ & SVN \\
\hline 2 & 8580 & PRT & 11795 & CZE & 94.7 & CZE & $80.6 \%$ & CZE & $89.8 \%$ & CZE & $67.5 \%$ & CZE \\
\hline 1 & 12327 & ESP & 13848 & ESP & $91.5 \%$ & ESP & $75.6 \%$ & ESP & $83.4 \%$ & ESP & $60.7 \%$ & ESP \\
\hline
\end{tabular}

a): Data taken from World Bank (1999), measuring GNP/cap, constant 1995 US-Dollars.

b): Data taken from World Bank (1999), measuring GNP/cap, PPP adjusted, constant 1995 US-Dollars.

c): Atkinson measure $(\varepsilon=1)$ computed on the basis of, and expressed as a share of GNP/cap, PPP adjusted (column 2).

d): Sen measure computed on the basis of, and expressed as a share of GNP/cap, PPP adjusted (column 2).

e): Atkinson measure $(\varepsilon=2)$ computed on the basis of, and expressed as a share of GNP/cap, PPP adjusted (column 2).

f): Dagum measure computed on the basis of, and expressed as a share of GNP/cap, PPP adjusted (column 2).

g): Income data of Moldova (MDA) from 1986, Russia (RUS) from 1990, and Slovenia (SVN) from 1992. 
Table 4: Welfare measures 1995

\begin{tabular}{|c|c|c|c|c|c|c|c|c|c|c|c|c|}
\hline \multirow{2}{*}{$\begin{array}{c}\text { Rank } \\
33\end{array}$} & \multicolumn{2}{|c|}{$\begin{array}{c}\text { GNP/cap }{ }^{\mathrm{a}} \\
\text { (exchange rate) }\end{array}$} & \multicolumn{2}{|c|}{$\begin{array}{c}\text { GNP/cap }^{\mathbf{b}} \\
\text { (PPP) }\end{array}$} & \multicolumn{2}{|c|}{ Atkinson $(\varepsilon=1)^{c}$} & \multicolumn{2}{|c|}{$\operatorname{Sen}^{d}$} & \multicolumn{2}{|c|}{ Atkinson $(\varepsilon=2)^{\mathrm{e}}$} & \multicolumn{2}{|c|}{ Dagum $^{f}$} \\
\hline & 572 & $\mathrm{CHN}$ & 1570 & MDA & $62.4 \%$ & KGZ & $44.7 \%$ & KGZ & $38.5 \%$ & KGZ & $28.8 \%$ & KGZ \\
\hline 32 & 700 & MDA & 1930 & KGZ & $81.5 \%$ & MDA & $63.5 \%$ & MDA & $66.7 \%$ & MDA & $46.5 \%$ & MDA \\
\hline 31 & 727 & KGZ & 2080 & TKM & $69.8 \%$ & UKR & $52.6 \%$ & UKR & $51.4 \%$ & UKR & $35.7 \%$ & UKR \\
\hline 30 & 954 & TKM & 2430 & UKR & $82.4 \%$ & TKM & $64.2 \%$ & TKM & $68.4 \%$ & TKM & $47.3 \%$ & TKM \\
\hline 29 & 979 & UZB & 2450 & UZB & $84.6 \%$ & UZB & $62.2 \%$ & $\mathrm{CHN}$ & $64.8 \%$ & $\mathrm{CHN}$ & $45.1 \%$ & CHN \\
\hline 28 & 992 & IDN & 2620 & CHN & $80.7 \%$ & CHN & $66.7 \%$ & UZB & $71.9 \%$ & UZB & $50.0 \%$ & UZB \\
\hline 27 & 1085 & PHL & 3050 & IDN & $75.4 \%$ & PHL & $56.2 \%$ & PHL & $30.4 \%$ & PAN & $39.1 \%$ & PHL \\
\hline 26 & 1229 & KAZ & 3360 & JAM & $84.9 \%$ & IDN & $65.8 \%$ & IDN & $59.7 \%$ & PHL & $49.1 \%$ & IDN \\
\hline 25 & 1438 & ROM & 3370 & KAZ & $81.2 \%$ & JAM & $62.1 \%$ & JAM & $2 \%$ & BRA & $45.0 \%$ & JAM \\
\hline 24 & 1509 & BGR & 3380 & PHL & $85.3 \%$ & KAZ & $67.3 \%$ & KAZ & $73.9 \%$ & IDN & $25.0 \%$ & BRA \\
\hline 23 & 1550 & JAM & 3490 & LVA & $87.0 \%$ & LVA & $52.0 \%$ & RUS & $67.5 \%$ & JAM & $35.1 \%$ & RUS \\
\hline 22 & 1639 & UKR & 3770 & LTU & $81.0 \%$ & LTU & $55.1 \%$ & PER & $55.4 \%$ & PER & $38.1 \%$ & PER \\
\hline 21 & 1778 & BLR & 4160 & BLR & $73.5 \%$ & PER & $62.7 \%$ & LTU & $54.2 \%$ & RUS & $50.7 \%$ & KAZ \\
\hline 20 & 1850 & LTU & 4280 & PER & $71.6 \%$ & RUS & $69.0 \%$ & LVA & $73.0 \%$ & KAZ & $45.7 \%$ & LTU \\
\hline 19 & 2021 & $\mathrm{COL}$ & 4360 & ROM & 54.8 & BRA & $40.0 \%$ & BRA & $66.0 \%$ & LTU & $27.2 \%$ & COL \\
\hline 18 & 2304 & RUS & 4390 & RUS & $82.2 \%$ & EST & $42.8 \%$ & COL & $39.5 \%$ & $\mathrm{COL}$ & $27.5 \%$ & PAN \\
\hline 17 & 2428 & PER & 4430 & EST & $55.7 \%$ & PAN & $43.2 \%$ & PAN & $76.1 \%$ & LVA & $52.7 \%$ & LVA \\
\hline 16 & 2494 & LVA & 4560 & BGR & $88.9 \%$ & BLR & $64.6 \%$ & EST & $44.7 \%$ & THA & $32.0 \%$ & THA \\
\hline 15 & 2613 & CRI & 5700 & POL & $84.1 \%$ & BGR & $71.6 \%$ & BLR & $7.1 \%$ & EST & $47.7 \%$ & EST \\
\hline 14 & 2771 & THA & 6080 & BRA & $88.7 \%$ & ROM & $65.7 \%$ & BGR & $49.7 \%$ & CRI & $48.9 \%$ & BGR \\
\hline 13 & 2875 & PAN & 6340 & THA & $60.1 \%$ & $\mathrm{COL}$ & $48.5 \%$ & THA & $71.1 \%$ & BGR & $55.8 \%$ & BLR \\
\hline 12 & 2994 & MEX & 6430 & HUN & $64.4 \%$ & THA & $71.4 \%$ & ROM & $79.2 \%$ & BLR & $36.1 \%$ & CRI \\
\hline 11 & 3058 & POL & 6440 & CRI & $70.1 \%$ & CRI & $53.0 \%$ & CRI & $79.0 \%$ & ROM & $34.7 \%$ & MYS \\
\hline 10 & 3230 & EST & 6480 & $\mathrm{COL}$ & $69.8 \%$ & MYS & $51.5 \%$ & MYS & $48.3 \%$ & MEX & $33.1 \%$ & MEX \\
\hline 9 & 3261 & SVK & 6580 & PAN & $67.6 \%$ & MEX & $49.7 \%$ & MEX & $51.1 \%$ & MYS & $55.5 \%$ & ROM \\
\hline 8 & 3452 & VEN & 6940 & MYS & 88. & POL & $71.6 \%$ & POL & $51.6 \%$ & VEN & $36.2 \%$ & VEN \\
\hline 7 & 4032 & MYS & 6990 & SVK & $93.0 \%$ & HUN & $53.2 \%$ & VEN & $78.5 \%$ & $\mathrm{POL}$ & $55.8 \%$ & POL \\
\hline 6 & 4191 & HUN & 7300 & MEX & $71.0 \%$ & VEN & $77.4 \%$ & HUN & $86.5 \%$ & HUN & $63.1 \%$ & HUN \\
\hline 5 & 4349 & BRA & 8490 & VEN & $95.4 \%$ & SVK & $81.7 \%$ & SVK & $91.2 \%$ & SVK & $69.1 \%$ & SVK \\
\hline 4 & 4916 & CZE & 9920 & CZE & $90.7 \%$ & CZE & $73.4 \%$ & CZE & $83.3 \%$ & CZE & $58.0 \%$ & CZE \\
\hline 3 & 9526 & SVN & 11060 & SVN & 91. & SVN & $74.9 \%$ & SVN & $67.5 \%$ & PRT & $47.5 \%$ & PRT \\
\hline 2 & 10450 & PRT & 13100 & PRT & 82. & PRT & $64.4 \%$ & PRT & $84.0 \%$ & SVN & $59.9 \%$ & SVN \\
\hline 1 & 14145 & ESP & 14910 & ESP & $85.6 \%$ & ESP & $67.5 \%$ & ESP & $73.5 \%$ & ESP & $51.0 \%$ & ESP \\
\hline
\end{tabular}

a): Data taken from World Bank (1999), measuring GNP/cap, constant 1995 US-Dollars.

b): Data taken from World Bank (1999), measuring GNP/cap, PPP adjusted, constant 1995 US-Dollars.

c): Atkinson measure $(\varepsilon=1)$ computed on the basis of, and expressed as a share of GNP/cap, PPP adjusted (column 2).

d): Sen measure computed on the basis of, and expressed as a share of GNP/cap, PPP adjusted (column 2).

e): Atkinson measure $(\varepsilon=2)$ computed on the basis of, and expressed as a share of GNP/cap, PPP adjusted (column 2).

f): Dagum measure computed on the basis of, and expressed as a share of GNP/cap, PPP adjusted (column 2). 
Table 5: The nature of Inequality in Transition and Non-Transition countries 1988, 1995

\begin{tabular}{|c|c|c|c|c|c|c|}
\hline \multirow[b]{2}{*}{ Country } & \multicolumn{3}{|c|}{1988} & \multicolumn{3}{|c|}{1995} \\
\hline & $\begin{array}{c}\text { Gini } \\
\text { coefficient }\end{array}$ & \begin{tabular}{|c} 
Income share \\
of poorest \\
quintile
\end{tabular} & $\begin{array}{c}\text { Atkinson }(\varepsilon=2) \\
\text { - Dagum }\end{array}$ & $\begin{array}{c}\text { Gini } \\
\text { coefficient }\end{array}$ & $\begin{array}{c}\text { Income share } \\
\text { of poorest } \\
\text { quintile }\end{array}$ & $\begin{array}{c}\text { Atkinson }(\varepsilon=2) \\
\text { - Dagum }\end{array}$ \\
\hline Bulgaria & 23.3 & $10.63 \%$ & $23.9 \%$ & 34.3 & $7.11 \%$ & $22.2 \%$ \\
\hline Belarus & 22.8 & $10.48 \%$ & $23.3 \%$ & 28.4 & $8.70 \%$ & $23.4 \%$ \\
\hline Brazil & 56.2 & $2.70 \%$ & $7.2 \%$ & 60.1 & $2.48 \%$ & $8.3 \%$ \\
\hline China & 34.9 & $6.60 \%$ & $20.0 \%$ & 37.8 & $6.02 \%$ & $19.7 \%$ \\
\hline Colombia & 51.2 & $3.70 \%$ & $13.7 \%$ & 57.2 & $3.10 \%$ & $12.3 \%$ \\
\hline Costa Rica & 42.0 & $4.40 \%$ & $13.9 \%$ & 47.0 & $3.99 \%$ & $13.6 \%$ \\
\hline Czech Republic & 19.4 & $11.92 \%$ & $22.3 \%$ & 26.6 & $10.50 \%$ & $25.3 \%$ \\
\hline Spain & 24.4 & $9.49 \%$ & $22.7 \%$ & 32.5 & $7.54 \%$ & $22.6 \%$ \\
\hline Estonia & 23.0 & $9.99 \%$ & $22.5 \%$ & 35.4 & $6.13 \%$ & $19.4 \%$ \\
\hline Hungary & 21.0 & $11.42 \%$ & $23.3 \%$ & 22.6 & $10.62 \%$ & $23.4 \%$ \\
\hline Indonesia & 32.0 & $7.99 \%$ & $22.8 \%$ & 34.2 & $8.37 \%$ & $24.9 \%$ \\
\hline Jamaica & 43.2 & $5.41 \%$ & $19.3 \%$ & 37.9 & $6.82 \%$ & $22.4 \%$ \\
\hline Kazakhstan & 25.7 & $9.47 \%$ & $23.2 \%$ & 32.7 & $7.49 \%$ & $22.3 \%$ \\
\hline Kyrgyz Republic & 26.0 & $10.57 \%$ & $24.7 \%$ & 55.3 & $2.69 \%$ & $9.7 \%$ \\
\hline Lithuania & 22.5 & $10.64 \%$ & $23.3 \%$ & 37.3 & $6.21 \%$ & $20.4 \%$ \\
\hline Latvia & 22.5 & $10.44 \%$ & $22.9 \%$ & 31.0 & $8.04 \%$ & $23.4 \%$ \\
\hline Moldova & 24.1 & $9.96 \%$ & $23.2 \%$ & 36.5 & $6.38 \%$ & $20.2 \%$ \\
\hline Mexico & 55.0 & $3.20 \%$ & $11.8 \%$ & 50.3 & $4.13 \%$ & $15.2 \%$ \\
\hline Malaysia & 48.4 & $4.58 \%$ & $16.9 \%$ & 48.5 & $4.45 \%$ & $16.4 \%$ \\
\hline Panama & 56.5 & $2.00 \%$ & $3.0 \%$ & 56.8 & $1.97 \%$ & $2.9 \%$ \\
\hline Peru & 42.8 & $6.20 \%$ & $21.8 \%$ & 44.9 & $4.88 \%$ & $17.4 \%$ \\
\hline Philippines & 45.7 & $5.20 \%$ & $18.7 \%$ & 43.8 & $5.85 \%$ & $20.6 \%$ \\
\hline Poland & 25.6 & $9.71 \%$ & $23.8 \%$ & 28.4 & $8.37 \%$ & $22.7 \%$ \\
\hline Portugal & 36.8 & $5.70 \%$ & $17.9 \%$ & 35.6 & $6.14 \%$ & $20.0 \%$ \\
\hline Romania & 23.3 & $9.97 \%$ & $22.8 \%$ & 28.6 & $8.74 \%$ & $23.5 \%$ \\
\hline Russia & 23.8 & $9.91 \%$ & $22.9 \%$ & 48.0 & $4.86 \%$ & $19.1 \%$ \\
\hline Slovakia & 19.5 & $11.89 \%$ & $22.4 \%$ & 18.3 & $12.55 \%$ & $22.2 \%$ \\
\hline Slovenia & 21.5 & $10.49 \%$ & $21.0 \%$ & 25.1 & $10.10 \%$ & $24.1 \%$ \\
\hline Thailand & 47.4 & $4.10 \%$ & $13.6 \%$ & 51.5 & $3.70 \%$ & $12.7 \%$ \\
\hline Turkmenistan & 26.4 & $10.50 \%$ & $24.8 \%$ & 35.8 & $6.70 \%$ & $21.2 \%$ \\
\hline Ukraine & 23.3 & $10.31 \%$ & $23.3 \%$ & 47.4 & $4.27 \%$ & $15.7 \%$ \\
\hline Uzbekistan & 28.2 & $8.97 \%$ & $23.8 \%$ & 33.3 & $7.28 \%$ & $21.9 \%$ \\
\hline Venezuela & 45.2 & $4.73 \%$ & $16.8 \%$ & 46.8 & $4.33 \%$ & $15.4 \%$ \\
\hline
\end{tabular}

Note: Columns three and six indicate the absolute difference in percentage points pf PPP per capita income between the Atkinson $(\varepsilon=2)$ and the Dagum measure expressed in percentages (column 5 minus column 6 in Table 3 and Table 4 , respectively). 
Table 6: The Determinants of the Gini Coefficients

\begin{tabular}{lcc}
\hline & $(1)$ & $(2)$ \\
\hline Expenditure & $-5.03(-12.7)$ & $-4.75(-12.2)$ \\
Net Income & $-2.99(-11.9)$ & $0.38(0.9)$ \\
Unknown Income & $0.30(1.0)$ & $0.53(1.7)$ \\
Household & $1.38(6.2)$ & $1.55(7.1)$ \\
Unit Unknown & $1.50(1.9)$ & $1.41(1.8)$ \\
Family & $0.65(1.3)$ & $0.51(1.1)$ \\
Equivalized & $-2.01(-6.4)$ & $-1.63(-5.3)$ \\
Primary Source not known & $0.29(0.7)$ & $0.19(0.5)$ \\
No consistent source & $-0.87(-4.1)$ & $-0.96(-4.6)$ \\
OECD * Net Income & & $-4.80(-10.3)$ \\
Constant & $36.52(164.6)$ & $36.45(167.4)$ \\
N & 2855 & 2855 \\
R-Squared & 0.17 & 0.20 \\
\hline
\end{tabular}

Note: Regressions include 'accept' and 'ps' and 'cs' coded data from Deininger and Squire (1996) and from Wider (1999). The regression is a fixed-effects regression, with t-statistics in parentheses.

Table 7: Change in Rankings due to Adjusted Gini Coefficients

\begin{tabular}{c|rcccc}
\hline & No change & 1 Rank & 2 Ranks & 3 Ranks & 4+ Ranks \\
\hline Sen Measure & & & & & \\
1980 & 16 & 2 & 0 & 0 & 0 \\
1988 & 31 & 2 & 0 & 0 & 0 \\
1995 & 25 & 6 & 2 & 0 & 0 \\
Dagum Measure & & & & 0 & 0 \\
1980 & 12 & 6 & 0 & 0 & 0 \\
1988 & 29 & 4 & 0 & 0 & 0 \\
1995 & 21 & 8 & 3 & & 0 \\
\hline
\end{tabular}

Note: Mexico is the country, that looses 4 ranks in the Dagum measure in 1995. This is mainly due to the fact that the original Gini coefficient was based on expenditures per capita and has been adjusted to disposable income per capita by adding nearly 5 percentage points. 
Table 8: Change of social Well-being Indicators in Transition Countries

\begin{tabular}{|c|c|c|c|c|c|c|c|c|c|c|c|c|}
\hline \multirow{3}{*}{ Country } & \multicolumn{4}{|c|}{$\begin{array}{c}\text { Life expectancy } \\
\text { in years }\end{array}$} & \multicolumn{2}{|c|}{$\begin{array}{c}\text { Mortality } \\
\text { rate }^{\mathrm{a}}\end{array}$} & \multicolumn{2}{|c|}{$\begin{array}{c}\text { School } \\
\text { enrolment }^{\mathrm{b}}\end{array}$} & \multicolumn{2}{|c|}{$\begin{array}{c}\text { Transition } \\
\text { index }\end{array}$} & \multicolumn{2}{|c|}{$\begin{array}{c}\text { Freedom House } \\
\text { Index }^{\mathrm{d}}\end{array}$} \\
\hline & \multicolumn{2}{|c|}{1988} & \multicolumn{2}{|c|}{1998} & \multirow{2}{*}{1989} & \multirow{2}{*}{1998} & \multirow{2}{*}{1989} & \multirow{2}{*}{1993} & \multirow{2}{*}{1994} & \multirow{2}{*}{1997} & \multirow{2}{*}{ 1988-89 } & \multirow{2}{*}{ 1999-00 } \\
\hline & Female & Male & Female & Male & & & & & & & & \\
\hline Bulgaria & $75^{\mathrm{e}}$ & $68^{\mathrm{e}}$ & 75 & 67 & 18 & 15 & 77 & 70 & 2.5 & 2.8 & $7,7 \mathrm{NF}$ & $2,3 \mathrm{~F}$ \\
\hline Belarus & 76 & 67 & 74 & 63 & 15 & 14 & 98 & 91 & 1.7 & 1.4 & $6,5 \mathrm{NF}^{\mathrm{h}}$ & $6,6 \mathrm{NF}$ \\
\hline Czech Republic & 75 & 68 & 78 & 71 & 12 & 6 & 93 & 92 & 3.5 & 3.5 & $7,6 \mathrm{NF}^{\mathrm{i}}$ & $1,2 \mathrm{~F}$ \\
\hline Estonia & 75 & 67 & 75 & 64 & 19 & 12 & 126 & 94 & 3.3 & 3.4 & $6,5 \mathrm{NF}^{\mathrm{h}}$ & $1,2 \mathrm{~F}$ \\
\hline Hungary & 74 & 66 & 75 & 66 & 18 & 12 & 75 & 94 & 3.3 & 3.7 & $5,4 \mathrm{PF}$ & $1,2 \mathrm{~F}$ \\
\hline Kazakhstan & 73 & 65 & 70 & 59 & - & 29 & 101 & 92 & 1.7 & 2.7 & $6,5 \mathrm{NF}^{\mathrm{h}}$ & $6,5 \mathrm{NF}$ \\
\hline Kyrgyz Republic & $70^{\mathrm{e}}$ & $62^{\mathrm{e}}$ & 71 & 63 & 47 & 41 & 102 & 90 & 2.8 & 2.8 & $6,5 \mathrm{NF}^{\mathrm{h}}$ & $5,5 \mathrm{PF}$ \\
\hline Lithuania & 77 & 68 & 77 & 67 & 14 & 12 & 95 & 81 & 3.0 & 3.1 & $6,5 \mathrm{NF}^{\mathrm{h}}$ & $1,2 \mathrm{~F}$ \\
\hline Latvia & 75 & 66 & 76 & 64 & 15 & 19 & 97 & 87 & 2.8 & 3.2 & $6,5 \mathrm{NF}^{\mathrm{h}}$ & $1,2 \mathrm{~F}$ \\
\hline Moldova & 71 & 64 & 70 & 63 & - & 22 & 83 & 84 & 2.2 & 2.6 & $6,5 \mathrm{NF}^{\mathrm{h}}$ & 2, $4 \mathrm{PF}$ \\
\hline Poland & 76 & 67 & 77 & 69 & 22 & 11 & 82 & 94 & 3.3 & 3.4 & $5,5 \mathrm{PF}$ & $1,2 \mathrm{~F}$ \\
\hline Romania & 72 & 67 & 73 & 66 & 35 & 25 & 101 & 79 & 2.7 & 2.7 & $7,7 \mathrm{NF}$ & $2,2 \mathrm{~F}$ \\
\hline Russia & 74 & 65 & 73 & 61 & 22 & 20 & 95 & 87 & 2.7 & 3.0 & $6,5 \mathrm{NF}^{\mathrm{h}}$ & 4, $5 \mathrm{PF}$ \\
\hline Slovakia & 76 & 67 & 77 & 69 & 16 & 10 & - & 89 & 3.3 & 3.3 & $7,6 \mathrm{NF}^{\mathrm{i}}$ & $1,2 \mathrm{~F}$ \\
\hline Slovenia & $76^{e}$ & $68^{e}$ & 79 & 71 & 10 & 7 & 90 & 90 & 3.2 & 3.2 & $2,3 \mathrm{~F}^{\mathrm{g}}$ & $1,2 \mathrm{~F}$ \\
\hline Turkmenistan & 69 & 62 & 70 & 63 & - & 44 & - & - & 1.2 & 1.5 & $6,5 \mathrm{NF}^{\mathrm{h}}$ & $7,7 \mathrm{NF}$ \\
\hline Ukraine & 75 & 66 & 73 & 62 & - & 17 & 95 & 91 & 1.3 & 2.4 & $6,5 \mathrm{NF}^{\mathrm{h}}$ & $3,4 \mathrm{PF}$ \\
\hline Uzbekistan & 71 & 66 & 73 & 66 & - & 29 & 101 & 94 & 2.0 & 2.0 & $6,5 \mathrm{NF}^{\mathrm{h}}$ & $7,6 \mathrm{NF}$ \\
\hline World & $67^{\mathrm{e}}$ & $63^{\mathrm{e}}$ & 69 & 65 & - & 75 & 54 & 62 & - & - & - & - \\
\hline $\begin{array}{l}\text { Latin-America \& } \\
\text { Caribbean }\end{array}$ & $70^{\mathrm{e}}$ & $64^{\mathrm{e}}$ & 73 & 67 & - & 38 & 48 & 49 & - & - & - & - \\
\hline High Income & $79^{\mathrm{e}}$ & $72^{e}$ & 81 & 75 & - & 6 & 94 & 105 & - & - & - & - \\
\hline Middle Income & $70^{\mathrm{e}}$ & $65^{\mathrm{e}}$ & 72 & 67 & $51^{\mathrm{f}}$ & 38 & 55 & 60 & _ & - & _ & - \\
\hline
\end{tabular}

${ }^{\mathrm{a}}$ : Measures the under five mortality rate per 1000 live births in percent.

b: Measures gross secondary enrolment rate in percent.

c: Composite index considering various dimensions of transition, including price liberalization, privatization, restructuring, competition policy, and reform of financial institutions.

$\mathrm{d}$ : The characters representing scores are, from left to right, political rights, civil liberties, and freedom status. Each of the first two is measured on a one-to-seven scale, with one representing the highest degree of freedom and seven the lowest. 'F', 'PF', and 'NF' respectively stand for 'free', 'partly free', and 'not free'.

e. 1987

f: 1990

g. $1991-92$

h: This rating is for Soviet Union.

i: This rating is for Czechoslovakia.

All data are taken from World Bank 1999, except for life expectancy data and mortality rates of 1998. Those are from World Bank 2000. Data on Transition Index and Freedom House Index are available on http://www.ebrd.org and http://www.freedomhouse.org, respectively. 
Figure 1:

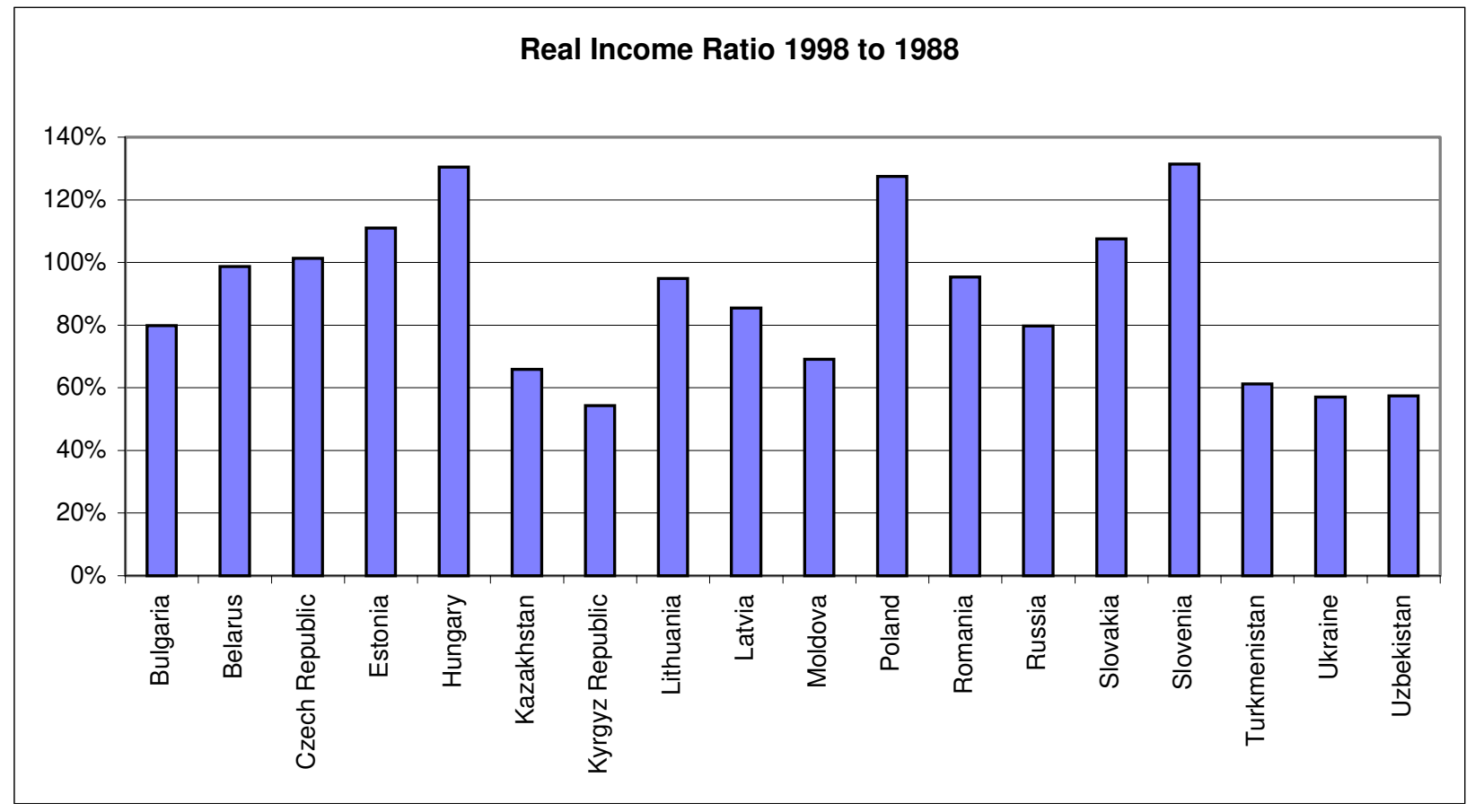

Source: World Bank (1999, 2000) 


\section{Figure 2:}
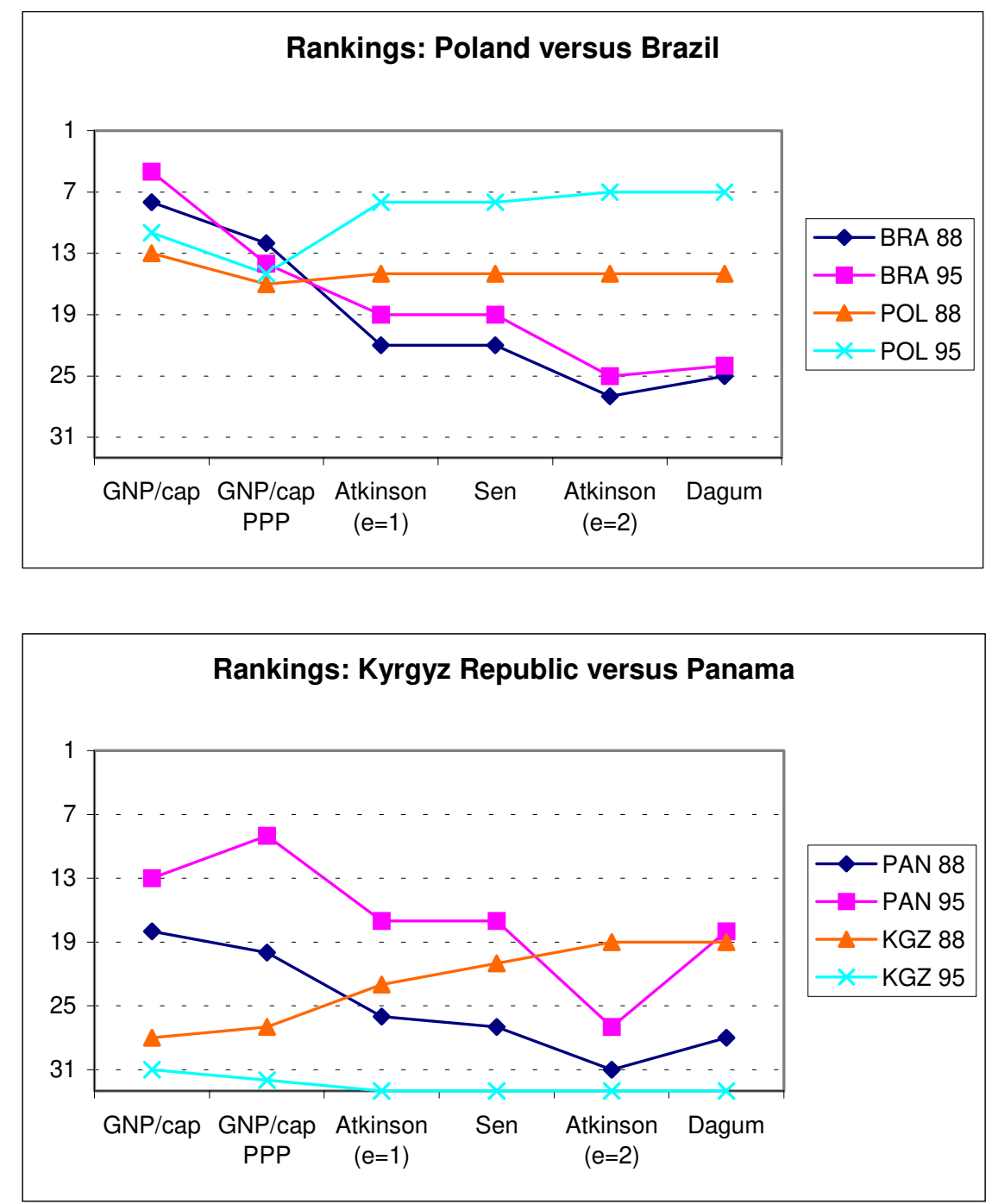
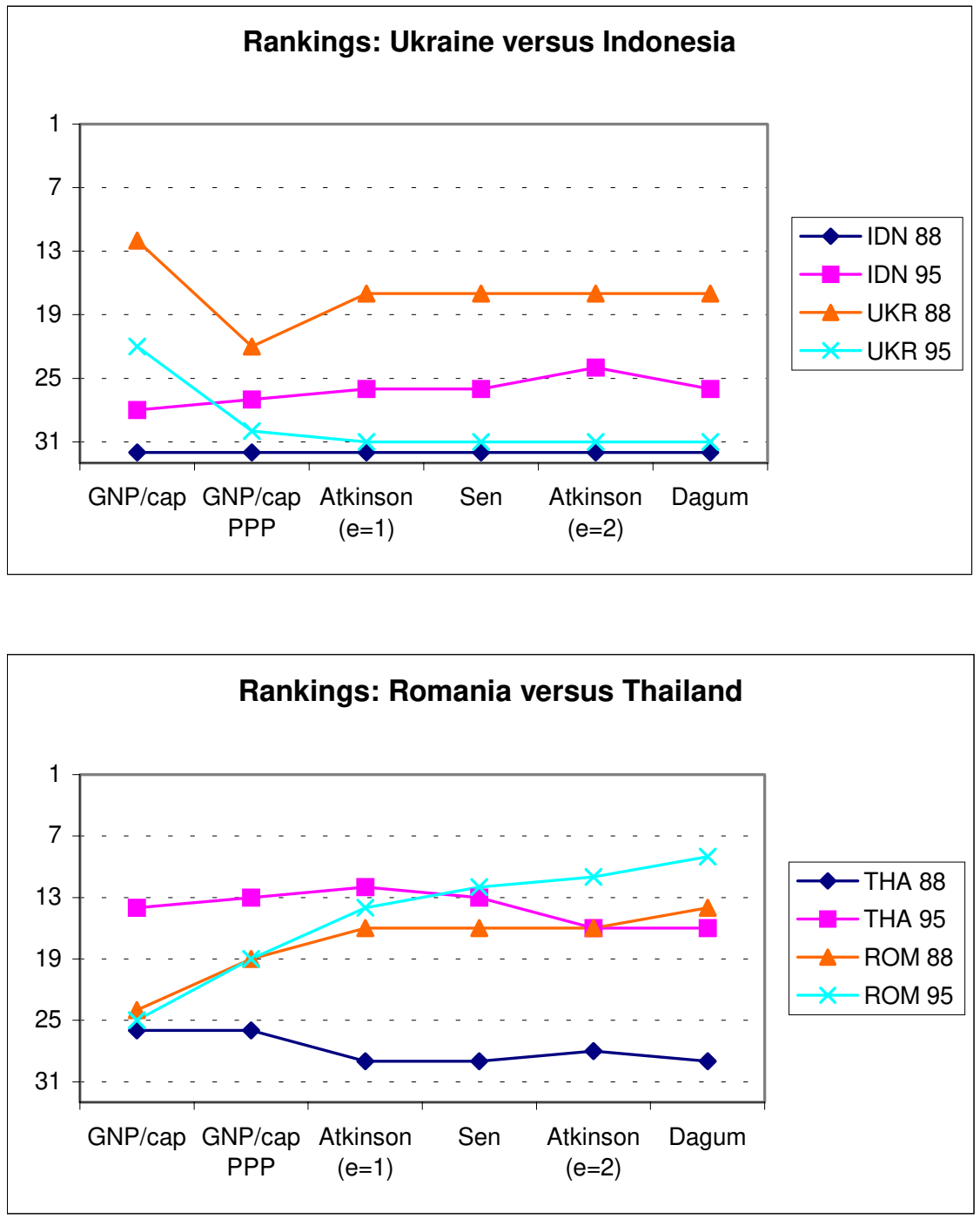
Figure 3:

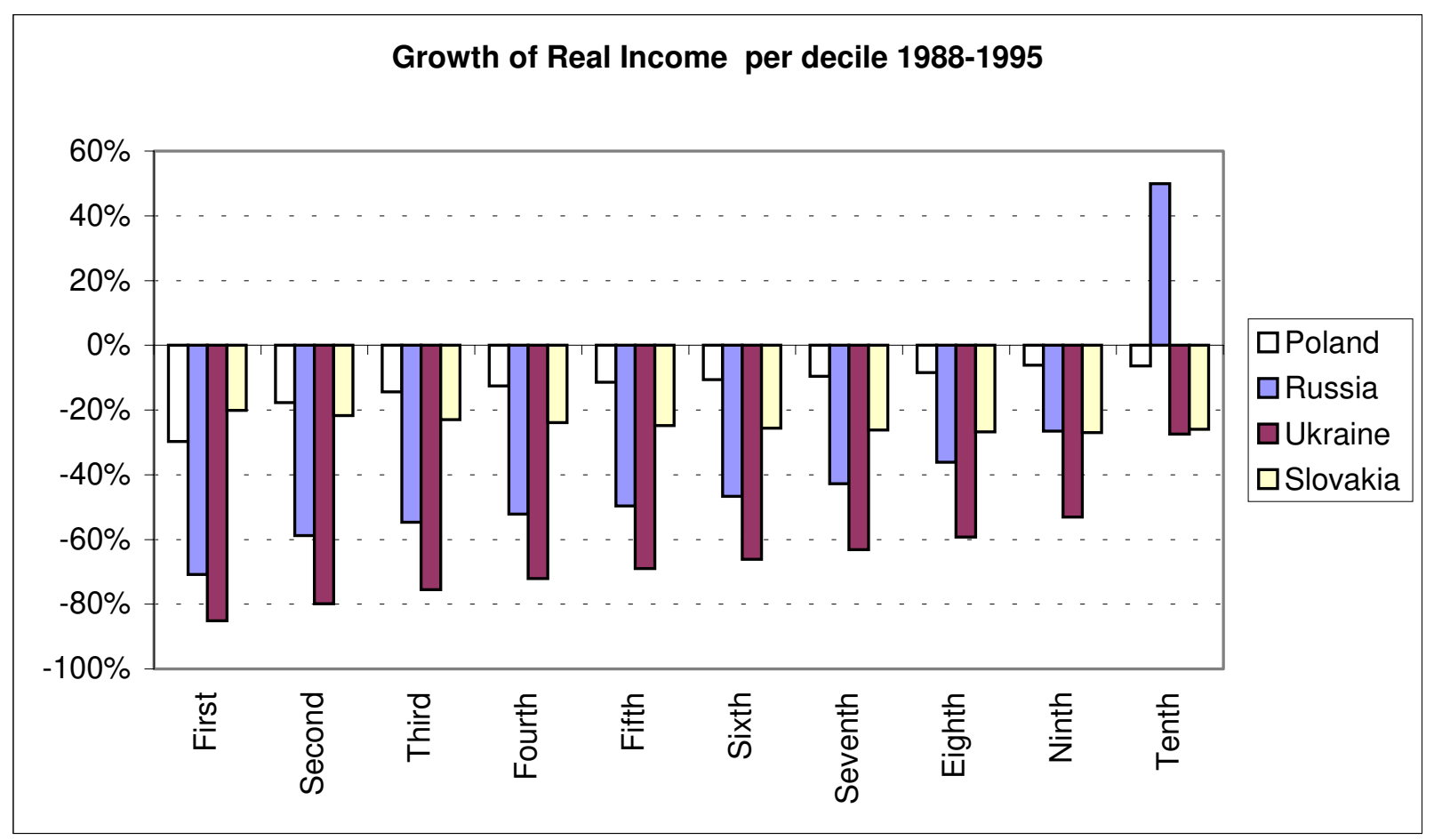

Figure 4:

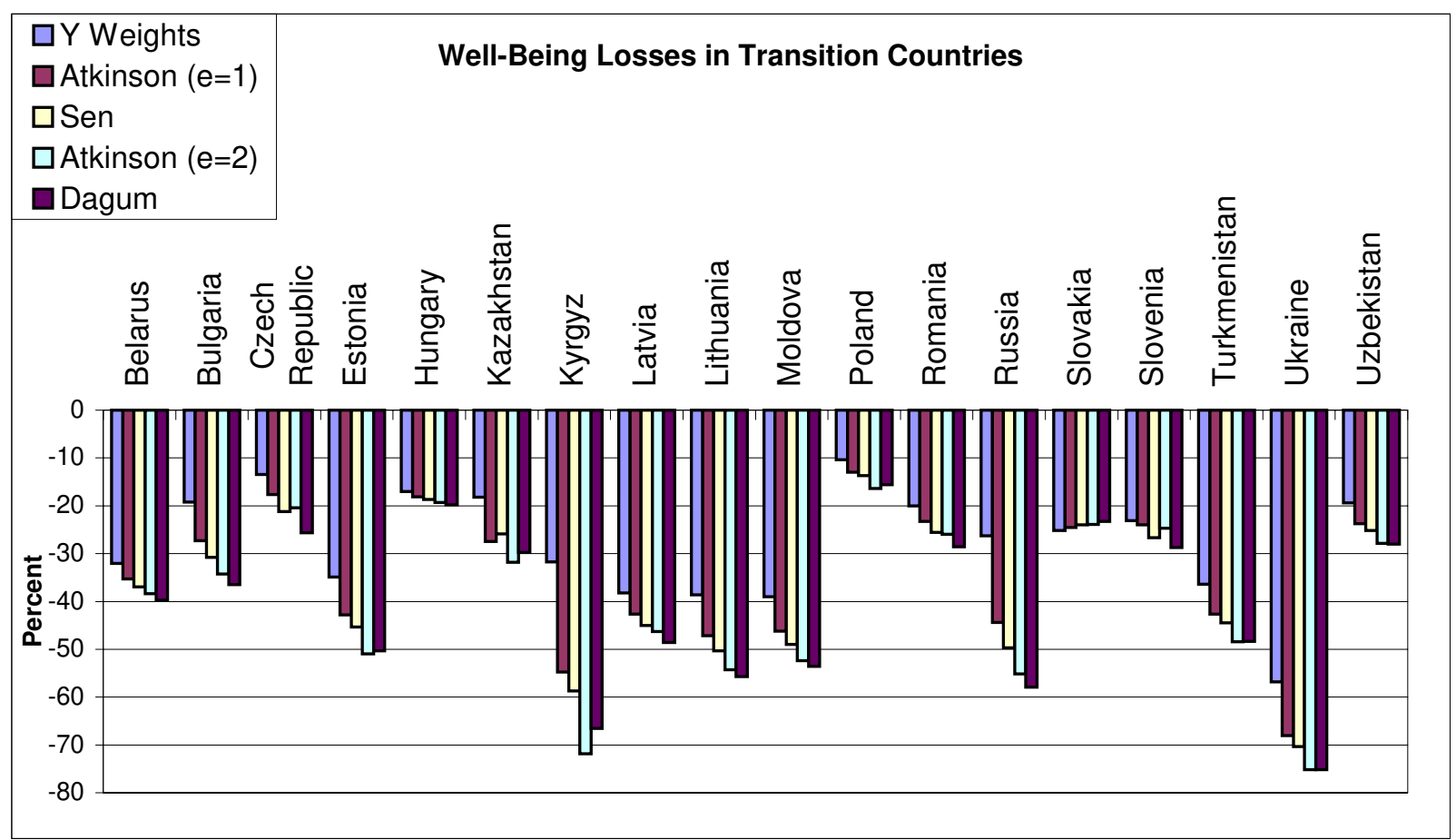

Note: There are slightly different time periods used, depending on data availability in Milanovic (1998). See also Table 1. 
Figure 5:

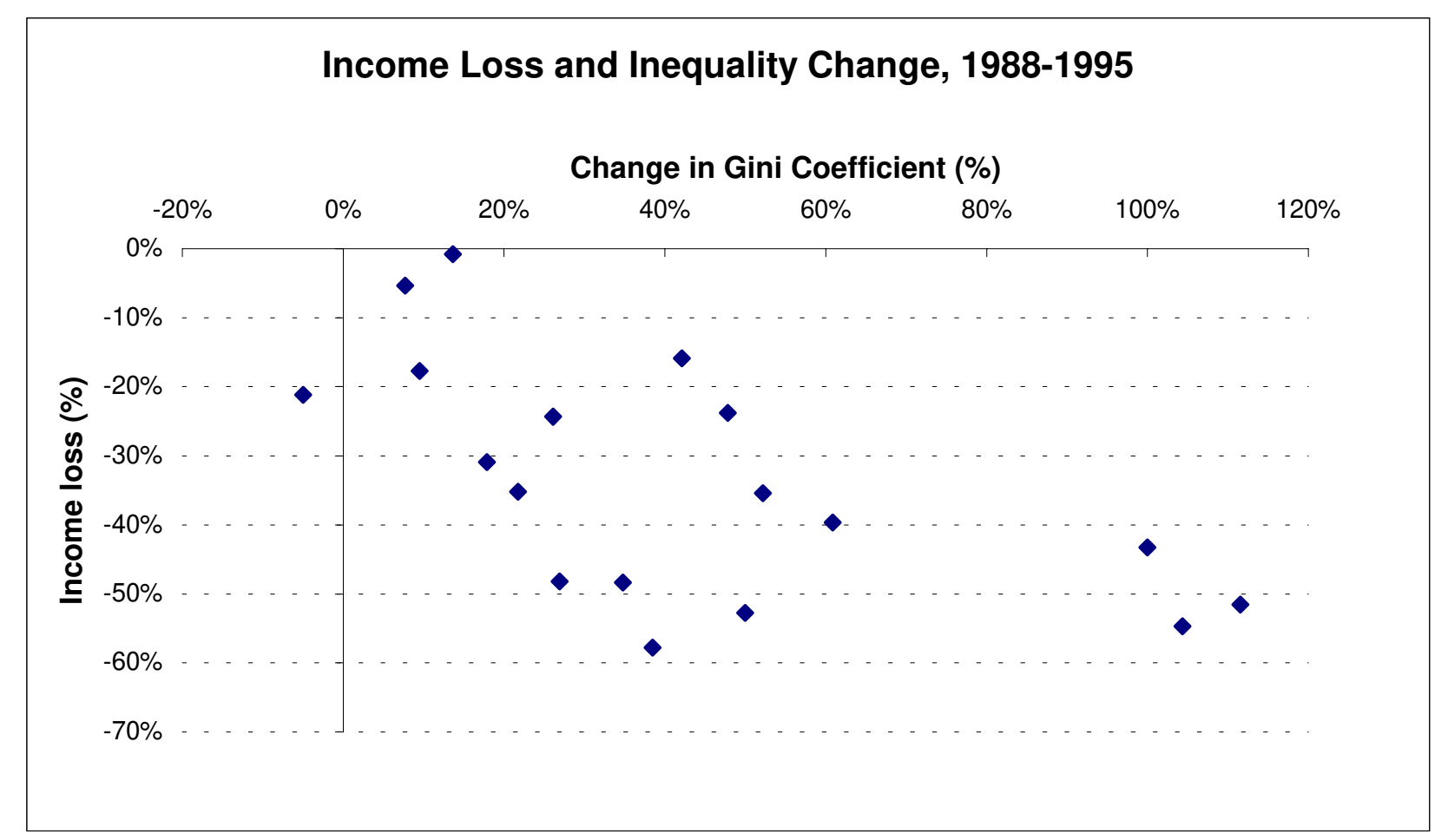


Appendix I: Country Acronyms

$\begin{array}{ll}\text { BGR } & \text { Bulgaria } \\ \text { BLR } & \text { Belarus } \\ \text { BRA } & \text { Brazil } \\ \text { CHN } & \text { China } \\ \text { COL } & \text { Colombia } \\ \text { CRI } & \text { Costa Rica } \\ \text { CZE } & \text { Czech Republic } \\ \text { ESP } & \text { Spain } \\ \text { EST } & \text { Estonia } \\ \text { HUN } & \text { Hungary } \\ \text { JAM } & \text { Jamaica } \\ \text { KAZ } & \text { Kazakhstan } \\ \text { KGZ } & \text { Kyrgyz Republic } \\ \text { LTU } & \text { Lithuania } \\ \text { MDA } & \text { Moldova } \\ \text { MEX } & \text { Mexico } \\ \text { MYS } & \text { Malaysia } \\ \text { PAN } & \text { Panama } \\ \text { PER } & \text { Peru } \\ \text { PHL } & \text { Philippines } \\ \text { POL } & \text { Poland } \\ \text { PRT } & \text { Portugal } \\ \text { ROM } & \text { Romania } \\ \text { RUS } & \text { Russian Federation } \\ \text { SVK } & \text { Slovak Republic } \\ \text { SVN } & \text { Slovenia } \\ \text { THA } & \text { Thailand } \\ \text { TKM } & \text { Turkmenistan } \\ \text { UKR } & \text { Ukraine } \\ \text { UZB } & \text { Uzbekistan } \\ \text { VEN } & \text { Venezuela }\end{array}$




\section{Appendix 2: Comparing Gini Coefficients from different Data Sources}

\begin{tabular}{|l|l|c|c|c|c|c|}
\hline \multicolumn{1}{|c|}{ Country } & \multicolumn{3}{|c|}{ Pre-Transition Period $^{\mathbf{a}}$} & \multicolumn{3}{c|}{ Post-Transition Period $^{\mathbf{b}}$} \\
\hline Bulgaria & $1989(23.3)$ & - & - & $1993(34.3)$ & - & - \\
Belarus & $1988(22.8)$ & $1989(23.8)$ & $1989(23)$ & $1995(28.4)$ & $1995(30)$ & - \\
Czech Republic & $1988(19.4)$ & - & $1989(20)$ & $1993(26.6)$ & - & $1996(25.8)^{\mathrm{c}}$ \\
Estonia & $1988(23.0)$ & $1989(29.9)$ & $1989(28)$ & $1995(35.4)$ & $1995(31)$ & - \\
Hungary & $1987(21.0)$ & $1987(24.4)$ & - & $1993(22.6)$ & $1993(27)$ & $1995(24.2)$ \\
Kazakhstan & $1988(25.7)$ & $1989(28.9)$ & - & $1993(32.7)$ & - & - \\
Kyrgyz Republic & $1988(26.0)$ & $1989(28.7)$ & $1989(27)$ & $1993(55.3)$ & $1993(43)$ & - \\
Lithuania & $1988(22.5)$ & $1989(27.8)$ & $1989(26)$ & $1994(37.3)$ & - & - \\
Latvia & $1988(22.5)$ & $1989(27.4)$ & $1989(26)$ & $1995(31.0)$ & - & - \\
Moldova & $1988(24.1)$ & $1989(25.8)$ & $1989(25)$ & $1993(36.5)$ & - & - \\
Poland & $1987(25.6)$ & $1989(26.8)$ & - & $1993(28.4)$ & $1993(31)$ & $1995(32.1)$ \\
Romania & $1989(23.3)$ & - & - & $1994(28.6)$ & $1994(33)$ & - \\
Russia & $1988(23.8)$ & $1989(27.8)$ & $1989(27)$ & $1993(48.0)$ & $1993(50)$ & $1995(38.1)^{\mathrm{c}}$ \\
Slovakia & $1988(19.5)$ & - & - & $1993(18.3)$ & - & - \\
Slovenia & $1987(21.5)$ & - & - & $1993(25.1)$ & - & - \\
Turkmenistan & $1988(26.4)$ & $1989(30.7)$ & $1989(28)$ & $1993(35.8)$ & - & - \\
Ukraine & $1988(23.3)$ & $1989(23.5)$ & $1989(23)$ & $1995(47.4)$ & $1995(44)$ & - \\
Uzbekistan & $1989(28.2)$ & $1989(30.4)$ & $1989(28)$ & $1993(33.3)$ & - & - \\
\hline
\end{tabular}

Gini coefficients are in parentheses.

a: Gini coefficients in column one are from Milanovic (1998) (mostly gross per capita income), column two from Atkinson, Micklewright (1992) (individual distribution of household per capita income), column three from Flemming, Micklewright (2000) (individual distribution of per capita household income). Flemming and Micklewright (2000) use the data from Atkinson and Micklewright (1992), but apply a slightly different procedure for calculating the Ginis.

b: Gini coefficients in column one and two are from Milanovic (1998) (disposable income and expenditures per capita, respectively), column three from Flemming, Micklewright (2000) (distribution of individuals per capita income).

c: There are other data sources available as well. In the case of the Czech Republic, Flemming and Micklewright provide data from the microcensus and the budget survey, respectively. Microcensus data are shown here. These Gini coefficients are higher for the period covered (1988-1997) in Flemming, Micklewright (2000). Ginis derived from the budget survey are not continuously available, but jump in 1993. In the case of Russia, the Gini computed from the Family Budget Survey is shown here, but data from the Russia Longitudinal Monitoring Survey are also presented in Flemming, Micklewright (2000). Milanovic also use this data source, and according to that survey, Gini coefficients in Russia are significantly higher. 


\section{References:}

Ahluwalia, M. S. and Chenery, H., The Economic Framework, in Chenery, H. et. al. (ed.), Redistribution with Growth, Oxford University Press, London, 1974.

Alesina, A. and Rodrick, D, Distributive Politics and Economic Growth, Quarterly Journal of Economics 109:465-490, 1994.

Arrow, K., Social Choice and Individual Values, New Haven, Yale University Press, 1963.

Atkinson, A. B., On the Measurement of Inequality, Journal of Economic Theory 2:244263, 1970.

and Brandolini, A., Promise and Pitfalls in the Use of Secondary Data Sets: Income Inequality in OECD Countries, Mimeographed 1999.

and Micklewright, J., Economic Transformation in Eastern Europe and the Distribution of Income, Cambridge University Press, Cambridge, 1992.

Banerjee, A., Policy making in an overconsuming World: Some Finger Exercises, Cambridge, Mimeographed, 1997.

Bardhan, K. and Klasen, S., UNDP's Gender-Related Indices: A Critical Review, World Development, Vol. 27, No. 6:985-1010, 1999.

Berry, A., Bourguignon, F, and Morrison, C., Global Economic Inequality and Its Trends Since 1950, In: Osberg, L., Economic Inequality and Poverty, M.E. Sharpe, Inc., Armonk, 1991.

Blackorby, C. and Donaldson, D., Measures of Relative Equality and Their Meaning in Terms of Social Welfare, Journal of Economic Theory 18:59-80, 1978.

Clarke, G. R. G., More Evidence on Income Distribution and Growth, Journal of Development Economics, Vol. 47, No. 2:403-27, 1995.

Dagum, C., On the Relationship between Income Inequality Measures and Social Welfare Functions, Journal of Econometrics 43:91-102, 1990.

Deaton, A., The Analysis of Household Surveys, The John Hopkins University Press, Baltimore, 1997.

Deininger, K. and Squire, L., A new Data Set Measuring Income Inequality, The World Bank Economic Review, Vol. 10, No. 3:565-91, 1996.

New Ways of Looking at Old Issues: Inequality and Growth, Working Paper, November 1997.

Bank, 1998.

Second Version of the Deininger and Squire Dataset, Washington, DC: The World

Dollar, D. and Kraay, A., Growth Is Good for the Poor, Working Paper, March 2000.

Easterlin, R., Will raising the incomes of all increase the happiness of all? Journal of Economic Behavior and Organization 27:35-47, 1995.

EBRD, European Bank for Reconstruction and Development, Transition Report, 2000.

Flemming, J. and Micklewright, J. Income Distribution, Economic Systems and Transition. In: Atkinson, A. and Bourguignon, F. (ed.), Handbook of Income Distribution (Vol. 1), North Holland, Amsterdam, 2000. 
Forbes, K., A Reassessment of the Relationship between Inequality and Growth, American Economic Review, Vol. 90 Nr. 4: 869-887, 2000.

Graaf, J. de V., Theoretical Welfare Economics, Cambridge University Press, London, 1957.

Grün, C. and Klasen, S., Growth, Income Distribution, and Well-Being: Comparisons across Space and Time, Mimeographed, Munich, 2000.

Klasen, S., Human Development and Women's Lives in a Restructured Eastern Bloc: Lessons from the Developing World, In: Schipke, A. and Taylor, A. (ed.): The Economics of Transition, Springer-Verlag, Berlin, 1994a.

Growth and Well-Being: Introducing Distribution-Weighted Growth Rates to Reevaluate U.S. Post-War Economic Performance, Review on Income and Wealth 40 (3): 251-72, 1994b.

Does Gender Inequality Reduce Growth and Development? Policy Research Report Working Paper Series No. 7, Washington, DC: The World Bank,1999.

Lundberg, M. and Squire,L., The Simultaneous Evolution of Growth and Inequality Mimeographed, Washington DC: The World Bank, 1999.

Milanovic, B., Income, Inequality, and Poverty during the Transition from Planned to Market Economy, World Bank, 1998.

NBER, National Bureau of Economic Research, Version 5.6 of the Penn World Tables, Cambridge, 2000.

Osberg and Sharpe, A., Estimates of an Index of Economic Well-Being for OECD Countries, paper prepared for the $26^{\text {th }}$ General Conference of the International Association for Research in Income and Wealth, 2000.

Persson, T. and Tabellini, G., Is Inequality harmful for growth?, American Economic Review, LXXXIV:600-621, 1994.

Rawls, J., A Theory of Justice, Harvard University Press, Cambridge, 1971.

Ray, D. Development Economics. Princeton University Press, Princeton, 1998.

Samuelson, P. A., Foundations of Economic Analysis, Harvard University Press, 1947.

Sen, A., Collective Choice and Social Welfare. Cambridge: Harvard University Press, 1973.

Oxford, 1982.

Real National Income, In: Choice, Welfare and Measurement, Basil Blackwell, , The Welfare Basis of Real Income Comparisons, In: Resources, Values, and Development, Harvard University Press, Cambridge, 1984. $548,1991$.

What Did You Learn in the World Today?, American Behavioral Scientist 34: 530, On Economic Inequality, Clarendon Press, Oxford, 1997.

Development as Freedom, Alfred A. Knopf, New York, 1999.

Summers, R. and Heston, A., The Penn World Table (Mark 5): An expanded Set of International Comparisons, 1950-1988, Quarterly Journal of Economics 106 (2): 327-68, 1991. 
UNDP, Human Development Report 1995, Oxford University Press, 1995.

UNDP, Human Development Report, 1996, Oxford University Press, 1996.

UNICEF, Public Policy and Social Conditions. Florence, 1993.

Wider, World Income Inequality Database, Beta 3, World Institute for Development Economics Research, Nov. 1999.

The World Bank, Word Development Indicators, 1999. 